\title{
The morphological diversity of long-necked lacewing larvae (Neuroptera: Myrmeleontiformia)
}

\author{
Gideon T. Haug, Viktor Baranov, Gil Wizen, Paula G. Pazinato, \\ Patrick Müller, Carolin Haug \& Joachim T. Haug
}

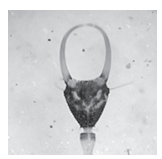

Thread-winged lacewings (Crocinae) nowadays occur in Africa, South America, Australia and the southern part of Eurasia. They have very distinct larvae, roughly resembling antlion larvae, yet, in many larvae the neck region is extremely elongated, earning them the name 'long-necked antlions'. Fossil lacewing larvae with recognisably long necks, but other characters differing from those of extant long-necked lacewing larvae, are known from Myanmar amber (100 mya, "Burmese amber"). We here summarise all already known larvae of extant thread-winged lacewings (53 specimens) and fossils of lacewing larvae with long necks ( 8 specimens). Moreover, we add further extant larvae of thread-winged lacewings ( 4 specimens) and fossil lacewing larvae with long necks (5 specimens), providing us a dataset of 70 specimens representing two distinct time slices. We compared these larvae concerning their shape by using outline analysis (based on elliptic Fourier transformation), including shape of the mandibles, the head, the neck, the trunk and the overall body shape. Fossil long-necked lacewing larvae differ from modern long-necked lacewing larvae especially in mandible and trunk shape. Their preservation in amber indicates that these larvae had a different ecology from their modern counterparts, which occur in sandy, arid environments. It remains unclear whether the fossil long-necked larvae are closely related to Crocinae. In any case these fossils represent a now extinct type of morphology, and most likely ecology. Key words: Nemopteridae, Crocinae, Neuroptera, shape analysis, fossil larvae, amber.

Haug, G.T., Baranov, V., Wizen, G., Pazinato, P.G., Müller, P., Haug, C. \& Haug, J.T. 2021. The morphological diversity of long-necked lacewing larvae (Neuroptera: Myrmeleontiformia). Bulletin of Geosciences 96(4), 431-457 (11 figures, electronic supplementary material). Czech Geological Survey, Prague. ISSN 1214-1119. Manuscript received July 23, 2020; accepted in revised form April 4, 2021; published online July 25, 2021; issued October 1, 2021.

Gideon T. Haug, Viktor Baranov \& Paula G. Pazinato, Ludwig-Maximilians-Universität München (LMU Munich), Biocenter, Großhaderner Str. 2, 82152 Planegg-Martinsried, Germany • Gil Wizen, 602-52 Park St. E, Mississauga, Ontario L5G 1M1, Canada • Patrick Müller, Kreuzbergstr. 90, 66482 Zweibrücken, Germany • Carolin Haug \& Joachim T. Haug, Ludwig-Maximilians-Universität München (LMU Munich), Biocenter, Großhaderner Str. 2, 82152 Planegg-Martinsried, Germany \& GeoBio-Center at LMU, Richard-Wagner-Str. 10, 80333 München, Germany; joachim.haug@palaeo-evo-devo.info

As has been widely recognised, there is a current decline of diversity in the ecologically important group of Insecta (e.g. Hallmann et al. 2017, Lister \& Garcia 2018, Seibold et al. 2019). To improve our understanding of this phenomenon, we can look at similar declines in diversity in ancient times as provided by the fossil record. In other words, we can compare the diversity of Insecta at different time slices. The fossil record of Insecta is especially attractive for such a type of comparison, as fossils with exceptional preservation, for example, preserved in amber, offer a very direct comparison to modern forms.

A major share of the modern-day diversity of Insecta is in fact the diversity of its ingroup Holometabola, with far more than half a million described species (Grimaldi \& Engel 2005). While the representatives of Holometabola are indeed very diverse, they share one characteristic feature: all immatures (besides the ultimate one) lack compound eyes, and instead (if not blind) possess specialised eyes, so-called stemmata (Beutel et al. 2013).

Similarly to the fact that the diversity of Insecta is mainly the diversity of Holometabola, the diversity of Holometabola is factually the diversity of some major ingroups, also known as "the big four" (although also here the true diversity lies in some deeper ingroups): 1) Hymenoptera: bees, ants and other wasps; 2) Coleoptera: beetles; 3) Lepidoptera: butterflies and moths; 4) Diptera: mosquitoes, midges, gnats and flies. Each of the "big four" comprises more than 100,000 formally described species (Grimaldi \& Engel 2005, Beutel et al. 2013, Engel et al. 2018).

From an ecological point of view, we need to consider that the diversity of ecosystem functions is in fact not only represented by well-known adult forms of Holometabola (Grimaldi \& Engel 2005, Marshall 2012, Hölker et al. 
2015, Baranov et al. 2016, Ulyshen 2018). Instead, the ecosystem diversity is also largely represented by the long-living and more individual-rich larvae, which are still poorly known in comparison to their adult forms (Baranov et al. 2019). Hence, for a true estimation of diversity in an ecological sense we need to also consider the diversity of larval forms. We therefore should attempt to compare larval diversity through time. Yet, this leads to a severe challenge: most diversity measures are based on taxonomic richness, but fossil larvae can often not easily be associated with adults, and therefore cannot be easily taxonomically treated (see discussion in e.g. Chen et al. 2014, Baranov et al. 2019, Haug \& Haug 2019). Therefore, larval diversity seems to be often estimated based on adult diversity, but this proved to be a very coarse proxy (Sinclair 1992, Baranov et al. 2019), and those larvae not associable with adults can still not be included into such studies. A possible way to address diversity on another level is morphological diversity. One simple way to quantify morphological diversity is shape diversity. Other aspects of morphology such as setation patterns or colouration are often not easily accessible in fossils, while shape usually is. Therefore, using shape as a proxy for the morphological diversity is an ideal method for including data from fossil larvae into analyses (see also discussion in Herrera-Flórez et al. 2020a).

Apart from the "big four", some of the now less species-rich ingroups of Holometabola seem to have played major roles in the early diversification of the group in ancient times. One of these is Neuroptera, the group of lacewings. The group comprises about 6,000 extant species (Winterton et al. 2010, Engel et al. 2018).

Most adult lacewings distantly resemble butterflies or dragonflies, with prominent fore- and hindwings, some of them to a striking degree, i.e. representatives of the exclusively fossil group Kalligrammatidae (Labandeira et al. 2016). Lacewing larvae are, with few exceptions, highly specialised ambush predators. They grasp prey items with a pair of stylets, each stylet being a compound of the mandible and the maxilla, allowing to inject venom, predigesting the prey and sucking out the liquified meal (Heckman 2017).

The probably most widely known ingroup of Neuroptera is Myrmeleontiformia, the group of antlion-like lacewings. As the name suggests, all myrmeleontiformians at least distantly resemble the namesakes of the group, antlions sensu stricto (Myrmeleontidae), which are especially famous for some of their larvae building trap funnels to bring their prey into their range (Badano \& Pantaleoni 2014, Engel et al. 2018).

Within Myrmeleontiformia, the representatives of the group Nemopteridae are known for the exquisite beauty and elegant flight patterns of their adults (Engel et al. 2018). Within Nemopteridae, there are two major lineages, the group Nemopterinae, the spoon-winged lacewings, and the group Crocinae, the thread-winged lacewings (e.g. Winterton et al. 2018, Vasilikopoulos et al. 2020). The group Crocinae is of particular interest in terms of larval diversity. Representatives of the group Crocinae are known for their very peculiar adults as well as exceptional larval forms. Crocinae has known representatives in Africa, South America, Australia and the southern part of Eurasia (Mansell 1981a, b, 1986, 2002; Engel et al. 2018). They seem to be largely restricted to deserts or other dry, arid habitats. As the name suggests, adults resemble adult antlions (and hence distantly dragonflies) but have thin, thread-like hindwings. The larvae differ from antlion larvae by possessing a prominent neck region between trunk and head, which is extraordinarily long in some of these; hence these have been referred to as long-necked lacewing larvae (Aspöck \& Aspöck 2007, Beutel et al. 2010). This long neck region between head and trunk forms a large sclerotised region, the so-called cervix.

Compared to other ingroups of Neuroptera, our knowledge of the larval forms of Crocinae is in fact quite good. Mansell (1986) stated that the group includes 47 species categorised in 17 named species groups (genera). From 21 of these species, also larvae seem to be known (see below for details).

So far, few fossils have been interpreted as larvae of Crocinae (Xia et al. 2015, p. 2; Zhang 2017). These larvae indeed are easily recognised as larvae of Myrmeleontiformia and, similar to some larvae of Crocinae, possess a long neck. Yet, as pointed out by Haug et al. (2019a), the case is indeed more complex as the fossil larvae resemble those of Crocinae in possessing a long neck, but otherwise exhibit characters of other groups of Neuroptera, hence represent a kind of Chimera-type larvae.

We here review the knowledge on extant larvae of Crocinae and fossil lacewing larvae with long necks, report new specimens, quantitatively infer the morphological diversity of extant and fossil forms and discuss evolutionary implications of these findings.

\section{Material and methods}

\section{Material}

Three basic types of source material were used for this study (Suppl. Tab. 1):

1) images of larvae of Crocinae or fossil lacewing larvae with long necks from the literature;

2) specimens of fossil lacewing larvae with long necks actually available for hands-on study (see below for provenance);

3) specimens photographed by various researchers or private enthusiasts. 
Additionally, one of the authors (GW) was able to keep larvae of Dielocroce hebraea Hölzel, 1975 in the lab and can hence report on field and lab observations of living animals.

Four new fossil specimens available for hands-on study that have never been depicted in any publication are presented here: BUB 1803 and BUB 1804 are part of the collection of one of the authors (PM) and are available for further study on request. PED 0085 and PED 0250 are part of the collection of the Palaeo-Evo-Devo (PED) Research Group, Ludwig-Maximilians-Universität München (LMU Munich), Germany. They were legally purchased on ebay.com from different traders (burmiteresearcher; burmitefossil).

One new fossil specimen was not available for handson study, but photos were provided (see below). The four extant specimens depicted here for the first time were also not available for hands-on study. The deposition of these specimens is not known to the authors. We are aware that specimens should ideally be deposited in public collections, yet for the study type performed here, this is seen as less problematic compared to taxonomic studies (see discussion in Haug et al. 2020a).

\section{Documentation and interpretation methods}

For type 1 material. - Images of larvae in the literature were digitally redrawn in Adobe Illustrator CS2. Specimens were partly idealised as only one half was redrawn, which was then mirrored. This was necessary for several reasons: 1) many drawings were originally already idealised to be symmetric, hence doing this for all specimens made the data in the set more comparable to each other. 2) For the fossils (see next point) the position in which the animal is preserved is often not ideal and therefore needs this type of idealisation to reduce the influence of preservation. 3) Shape analysis is sensitive to asymmetry aspects; idealising the drawing to a symmetric image removes this signal, which could otherwise dominate the analysis, masking the differences in focus of this study.

For type 2 material. - Specimens were documented on a Keyence VHX-6000 digital microscope. Four different settings of illumination were used. Either unpolarised ring light or cross-polarised coaxial light, each in combination with black and white background, was used. The image providing most details was used for further examination (Baranov et al. 2019, Haug \& Haug 2019). Specimens were immersed with a drop of water and covered by a cover slip to provide an even surface. Each image was recorded as a composite image, combining images in different focus levels, adjacent image details and various exposure times. Processing (fusion of stacks, merging of images, HDR) was performed with the built-in software (e.g. Haug et al. 2013, Hörnig et al. 2016). Resulting images were further optimised for histogram in Adobe Photoshop CS2. All differentiable structures were colour-marked to show the reader our interpretation.

For type 3 material. - The histogram of the images was optimised in Adobe Photoshop CS2.

\section{Outlines}

Outlines for five different structures were considered: mandible, head, neck, trunk, and total body without locomotory appendages ("legs"; Suppl. Figs 1-5). All outlines were drawn in Adobe Illustrator CS2.

For type 1 material. - Structures were extracted from the drawings. Mandibles were amended by a rounded base, as shape analysis is sensitive to straight cut-off edges.

For type 2 and 3 material. - Outlines were redrawn from the images. Similar to type 1 material, one side was redrawn and then mirrored (see above for the reasons for mirroring), besides for the outlines of the mandibles. Some specimens were preserved too far laterally to mirror them reliably; these were redrawn in original position and not included into the shape analyses.

\section{Shape analysis}

Shapes analyses of head, neck, trunk and total body were performed in $\mathrm{R}$ statistical and programming environment using the Momocs package (Bonhomme et al. 2014). The shapes of head, neck, trunk and total body were each characterized by 9 harmonics respectively. All data analyses were conducted in R version 3.4.1 (2017-06-30) "Single Candle" (R Core Team 2014).

For the analysis of the shape of the mandibles, we used SHAPE (Iwata \& Ukai 2002). The free software attributes a numerical sequence for each outline (a chain code). The chain codes are then normalized into Fourier Elliptical Descriptors (EFDs). The Fourier transformation was based on 20 harmonics (the simplest functions that could be retrieved from the chain codes), and normalized according to the position of the first harmonic. This means that all outlines were oriented accordingly to the major axis of the ellipse, which only works for elongated structures. Subsequently, a Principal Component Analysis (PCA) was performed on the 20 harmonics of the EFDs coefficients. The PCA was based on the variance-covariance matrix of the coefficients. The results of the PCA were saved on a spreadsheet and visualized in R (using the package ggplot2). 


\section{Phylogenetic frame}

As a frame for exploring shape, a phylogeny can proof very helpful. At least for the extant forms, there is one very recent analysis available (Lu et al. 2019). For the scatter plots, we distinguished distinct monophyletic subgroups to reveal patterns more easily. The subgroups were: 1) Veurise; 2) Concroce + [(Austrocroce + Carnarviana $)$ $+($ Josandreva + Croce $)]$, in short Concroce-Croce group; 3) Tjederia + (Thysanocroce + Laurhervasia $)$; 4) Amerocroce + Moranida; 5) Necrophylus + Dielocroce. All fossil forms were treated as a single additional group.

The phylogeny of the extant groups used here can be summarised as: Veurise $+\{$ Concroce-Croce group + $[$ Tjederia $+($ Thysanocroce + Laurhervasia $)]+[($ Amerocroce + Moranida $)+($ Necrophylus + Dielocroce $)]\}$.

\section{Results}

\section{Extant larvae of Crocinae}

All occurrences are listed chronologically. Cases in which the same specimen has been re-figured are also included chronologically with reference to the original occurrence. While this includes a certain redundancy, it should represent the most complete way of crossreferencing, avoiding interpreting the same specimen as two independent occurrences.

1) Roux (1833) briefly described and figured a larva (specimen 1, Fig. 1) with an extremely long neck, which he named Necrophylus arenarius in the text, but "Necrophilus arenarius" in the figure legend. The specimen was refigured by Westwood (1840, fig. 66.1) and Sharp (1895, fig. 306), both referring to it as "Necrophilus arenarius" (for taxonomic difficulties of the name, see Monserrat 2008). The drawing was also re-figured by MaxwellLefroy (1909a, fig. 73) and referenced as "Nemopterid larva". A simplified version was figured in Herrera-Flórez et al. (2020b, fig. 5d). Length was provided by a line next to the drawing, which should represent the length of the original animal; yet as we only have electronic versions available, we have no clear information about the size.

2) Westwood (1840, fig. 66.1) re-figured specimen 1, i.e. the drawing by Roux (1833). The drawing is quite small and rather simplified. In the text, the species name was referred to as "Necrophilus arenarius".

3) Schaum (1857) provided a drawing of a larva (specimen 2, Fig. 1) of Necrophylus arenarius Roux, 1833 (Roux 1833, fig. 1). The species is referred to as "Necrophilus arenarius". Additionally, close-ups of the stylet (Roux
1833, fig. 1a), the labial palps (Roux 1833, fig. 1b), the gut (Roux 1833, fig. 1c) and the nervous system (Roux 1833, fig. 1d) were provided. No direct indication of size for the entire larva was provided. Schaum (1857) had, according to text, about 20 specimens at hand, length variation was provided in "Lin.", i.e. "line". As it remains unclear which historical type of line as unit of length this refers to, the size remains unclear. The image was re-figured by Navás (1912, pl. 2), labelled as "Larve de Nemopteride".

4) Sharp (1895, fig. 306) re-figured specimen 1, i.e. the drawing by Roux (1833). The species name was referred to as "Necrophilus arenarius".

5) Maxwell-Lefroy (1909a, fig. 73) re-figured specimen 1, i.e. the drawing by Roux (1833). The larva was referred to as "Nemopterid larva".

6) Maxwell-Lefroy (1909b, unnumbered fig. on page 1006) figured a stage 1 larva (specimen 3 ) of Croce filipennis Westwood, 1841. The drawing is rather simplified in some aspects, but in outline exactly matches a drawing provided by Ghosh (1910). Although counter intuitive, given the date of publication, we consider the drawing by Maxwell-Lefroy (1909b) as a re-drawing and the one by Ghosh (1910) as the original (see next point).

7) Ghosh (1910, fig. 1) provided a drawing of a stage 1 larva (specimen 3, Fig. 1) of Croce filipennis Westwood, 1841. The drawing looks much like a better version of the drawing by Maxwell-Lefroy (1909b, unnumbered fig. on page 1006) and is considered to be the original. Length was stated to be slightly more than $1 \mathrm{~mm}$ including stylets.

Ghosh (1910, fig 2) also provided a drawing of a later stage larva (possibly stage 3, specimen 4, Fig. 1) of Croce filipennis. Length was stated to be about $7 \mathrm{~mm}$.

Additionally, Ghosh (1910, fig. 3) provided a drawing of a very late larva (prepupa). This latter specimen was depicted in lateral view and is not further considered here.

8) Imms (1911, fig. 1) provided a drawing of a stage 1 larva (specimen 5, Fig. 1) of Croce filipennis Westwood, 1841. Additionally, close-ups of the head (Imms 1911, fig. 4) and of specialised setae (Imms 1911, figs 5a, b) were provided. The total length of the larva was not provided with the figure legend. In the text, a size range between $1.4 \mathrm{~mm}$ and $1.77 \mathrm{~mm}$ and an average length of $1.5 \mathrm{~mm}$ is mentioned. The drawing was re-figured by Tjeder (1967, fig. 1964). A stage 2 larva was described, but not figured.

Imms (1911, fig. 2) also provided a drawing of a stage 3 (specimen 6, Fig. 1) larva of Croce filipennis Westwood, 1841. Total length of the larva was not provided with the 

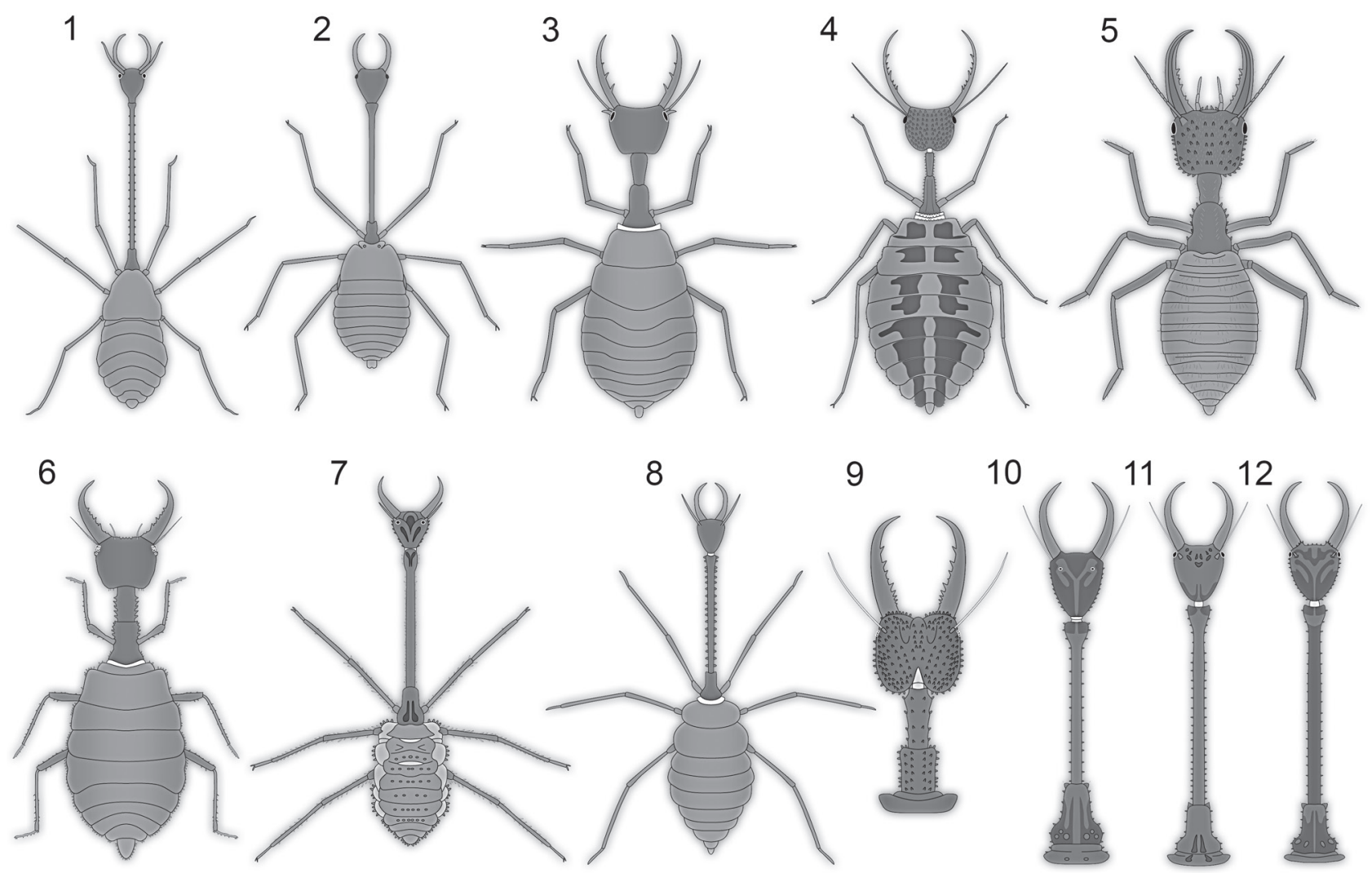

$9 \quad 10$

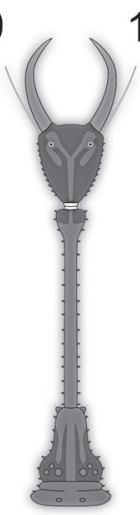

11
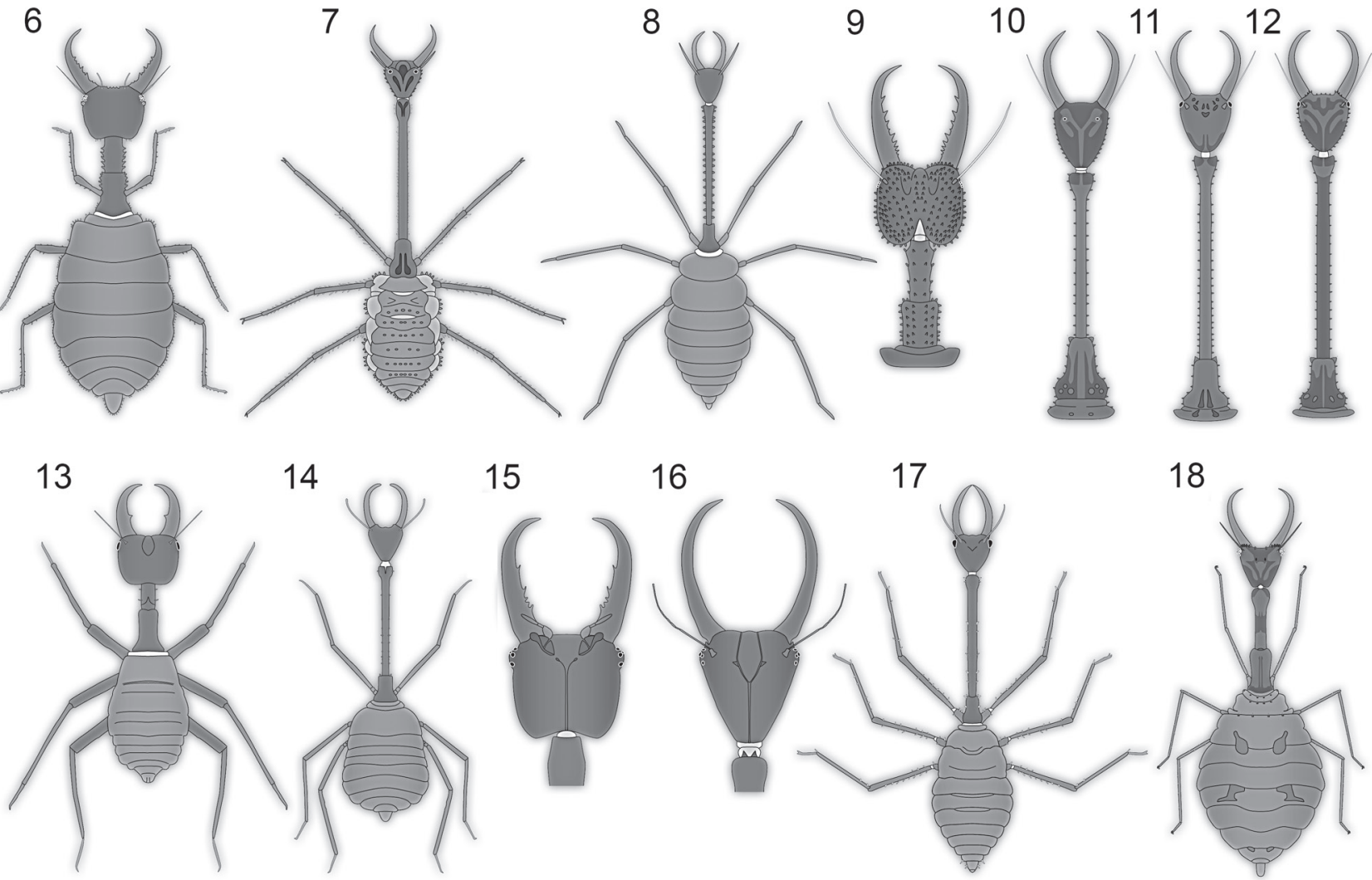

$15 \quad 16$

$16 \quad 17$
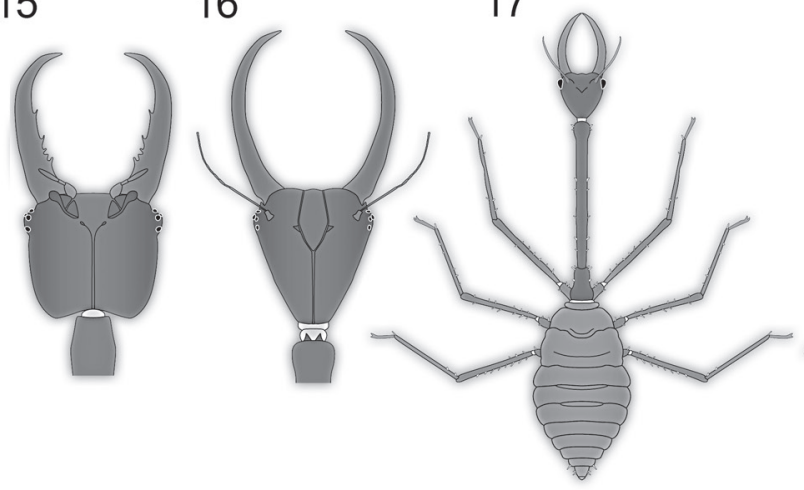

18

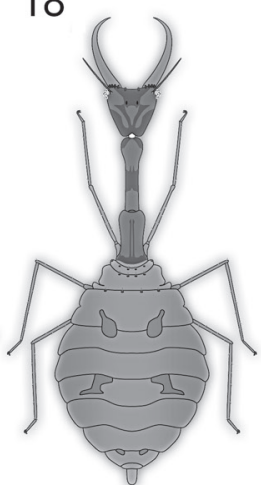

Figure 1. Larvae of thread-winged lacewings from the literature. Numbers refer to specimen numbers in the text. $11,2,7,8,11,12,14,16,17-$ Necrophylus arenarius Roux, 1833. -3-6, 9, 15 - Croce filipennis Westwood, 1841. 10 - Dielocroce baudii (Griffini, 1895). 13 - Dielocroce berlandi (Navás, 1936). 18 - Laurhervasia setacea (Klug, 1836). Drawings simplified from: 1 - Roux (1833); 2 - Schaum (1857); 3, 4 - Ghosh (1910); 5, 6 - Imms (1911); 7 - Wheeler (1929); 8 - Imms (1930); 9-12 - Withycombe (1923); 13, 14 - Pierre (1952); 15, 16 - MacLeod (1964); 17 Riek (1970); 18 - Mansell (1976). Drawings not to scale.

figure legend. In the text, a size range between $6.8 \mathrm{~mm}$ and $7.2 \mathrm{~mm}$ is mentioned. The drawing was re-figured by Imms (1923, fig. 394; also in later editions). The drawing was also re-figured by Tjeder (1967, fig. 1965) and labelled "Croce filipennis Westwood", by Gepp (1984, fig. $18 \mathrm{a}$, where the length was given as $8 \mathrm{~mm}$ ) and labelled as in Tjeder (1967), and also by Monserrat (2008, fig. 11b) and labelled "Croce".
9) Navás (1912, pl. 1, fig. 8) re-figured specimen 2, i.e. the drawing by Schaum (1857), labelled as "Larve de Nemopteride".

10) Step (1916, unnumbered fig. on page 111) provided a more artistic drawing apparently figuring larvae and adults of Necrophylus arenarius Roux, 1833. The drawing appears to be inspired by earlier drawings, yet represents 
more of an art piece (produced by Theo Carreras), rather than a precise depiction of an actual specimen. It is therefore not further considered here.

11) Eltringham (1923, pl. 1) provided a drawing of a larva (specimen 7) of Necrophylus arenarius Roux, 1833. Note: the plate is missing in the electronic version of the paper available by the publisher and was not directly seen by the authors; only a re-figured version of Wheeler (1929) was available. The specimen was referred to as "larva of Pterocroce storeyi". Length of the specimen was stated to be $8.5 \mathrm{~mm}$. The drawing was re-figured by Kimmins (1929, fig. 1b), labelled "Pterocroce storeyi Larva" and Wheeler (1929, fig. 1), labelled "Larva of Necrophylus arenarius Roux (Pterocroce storeyi Withycombe)".

12) Imms (1923) presumably re-figured specimen 6, i.e. the drawing by Imms (1911). We could not access the first edition, yet in the second edition (Imms 1930, fig. 394a) specimen 6 is shown. Imms (1930) furthermore showed a drawing of a stage 3 larva of Necrophylus arenarius Roux, 1833 (Imms 1930, fig. 395), referred to as "Pterocroce storeyi". The source of the drawing is given as "After Withycombe", without further reference. In the bibliography, three papers by Withycombe were cited (1922, $1923,1925)$. None of these includes a figure of an entire larva of $N$. arenarius. The drawing is also no re-figuring of any of the three other earlier figured specimens of N. arenarius (Roux 1833, Schaum 1857, Eltringham 1923), as the ratios of the body regions are quite different, i.e. the neck is shorter in relation to the trunk. We therefore consider this drawing as an additional specimen (specimen 8 , Fig. 1), possibly based on a personal communication between the author (Imms) and Withycombe. Length of the specimen was provided as magnification factor. According to this, the specimen was $8.6 \mathrm{~mm}$ in total length.

The figures also appear to be still present in the other editions of Imm's General Textbook of Entomology (published by various publishers; later editions expanded by other authors; e.g. 1924, 1925, 1934; $5^{\text {th }}$ edition 1942 ; $6^{\text {th }}$ edition $1946 ; 1948 ; 8^{\text {th }}$ edition 1951 ; $9^{\text {th }}$ edition 1957 ; $9^{\text {th }}$ edition $1960 ; 9^{\text {th }}$ edition $1964 ; 1970 ; 10^{\text {th }}$ edition 1977 ; 2000; 2017; for several of them we could not find out which edition they were), but with varying figure numbers (e.g. in $10^{\text {th }}$ edition, Richards \& Davies 1977 it is their figs 366a and 367).

13) Withycombe (1923, pl. 12, fig. 1) provided a drawing of a head of a stage 3 larva (specimen 9, Fig. 1) of Croce filipennis Westwood, 1841. There seems to be no indication of size. The drawing was re-figured by Withycombe (1925, pl. 40, fig. 10), labelled "Croce filipennis Westwood" and Tjeder (1967, fig. 1966), labelled "Croce filipennis (Westwood)".
Withycombe (1923) also provided a drawing of a head of a stage 3 larva (specimen 10, Fig. 1) of Dielocroce baudii (Griffini, 1895) (referred to as "Nina joppana Withycombe"; Withycombe 1923, pl. 12, fig. 2). Length of the specimen was stated to be $8-9 \mathrm{~mm}$, head $0.83 \mathrm{~mm}$, neck $2.28 \mathrm{~mm}$. The drawing was re-figured by Tjeder (1967, fig. 1967) and referenced as "Dielocroce joppana (Withycombe)". The drawing was additionally re-figured by Monserrat (2008, fig. $11 \mathrm{ma})$, referred to as "Dielocroce".

Furthermore, Withycombe (1923) provided a drawing of a head of a stage 3 larva (specimen 11, Fig. 1) of Necrophylus arenarius Roux, 1833 (referred to as "Pterocroce storeyi, light form", pl. 12, fig. 3). Length of the specimen was stated to be about $10 \mathrm{~mm}$, head $0.8 \mathrm{~mm}$, neck $2.7 \mathrm{~mm}$. The drawing was re-figured by Tjeder (1967, fig. 1968) referenced as "Pterocroce storeyi Withycombe". The drawing was additionally re-figured by Monserrat (2008, fig. $11 \mathrm{mb})$ and referred to as "Necrophylus $=$ (Pterocroce)".

Withycombe (1923, pl. 12, fig. 4) also provided a drawing of a head of stage 3 larva (specimen 12, Fig. 1) of Necrophylus arenarius Roux, 1833 (referenced as "Pterocroce storeyi, dark form"). Length of the specimen was stated to be about $10 \mathrm{~mm}$, head $0.8 \mathrm{~mm}$, neck $2.7 \mathrm{~mm}$. The drawing was re-figured by Monserrat (2008, fig. $11 \mathrm{mc}$ ) labelled as "Necrophylus $=($ Pterocroce $)$ ".

14) Withycombe (1925, pl. 40, fig. 10) re-figured specimen 9, i.e. a drawing by Withycombe (1923), although not citing this source. The specimen was labelled "Croce filipennis Westwood".

15) Kimmins (1929, fig. 1b) provided a figure of a larva of Necrophylus arenarius Roux, 1833 (labelled as "Pterocroce storeyi"). MacLeod (1964) cites Kimmins (1929) as providing "a new figure of the larva" (p. 435). Yet, by close comparison it appears to us that this is a re-drawing of specimen 7, i.e. the figure by Eltringham (1923), hence no new figure. The match of the two figures is extremely close. The positions of the left legs are identical, as are the folds on the trunk, the length of the neck and also position of the head appendages. Only the right appendages and the posterior end of the trunk deviate slightly. We therefore do not further consider this figure.

16) Wheeler (1929, fig. 1) re-figured specimen 7 (Fig. 1), i.e. the drawing by Eltringham (1923). The specimen was labelled "Larva of Necrophylus arenarius Roux (Pterocroce storeyi Withycombe)".

17) Pierre (1952, fig. 7) provided a drawing of the larva (specimen 13, Fig. 1) of Dielocroce berlandi (Navás, 1936), labelled as "Berlandus sahare Pierre, 1952". Size 

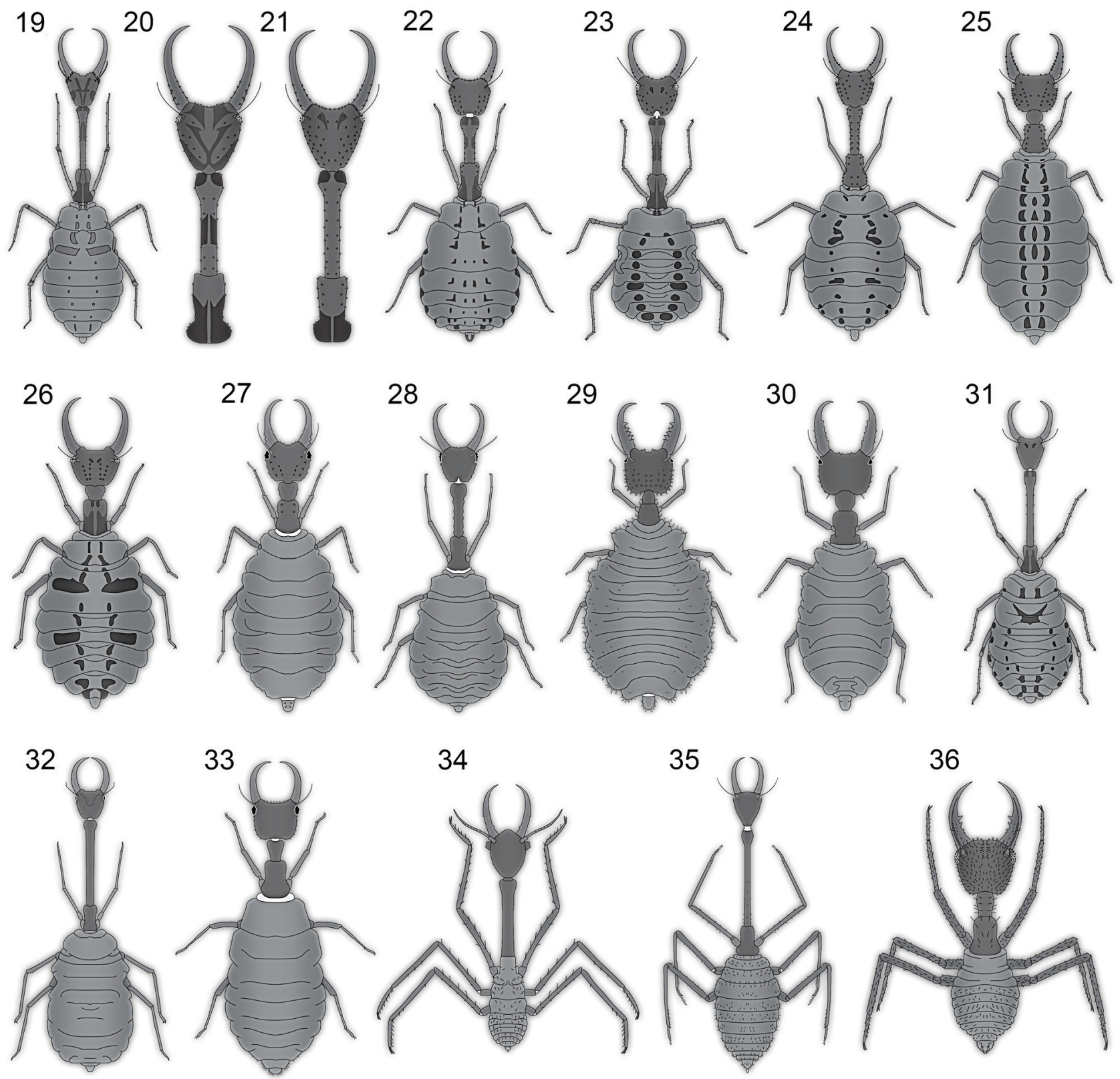

34
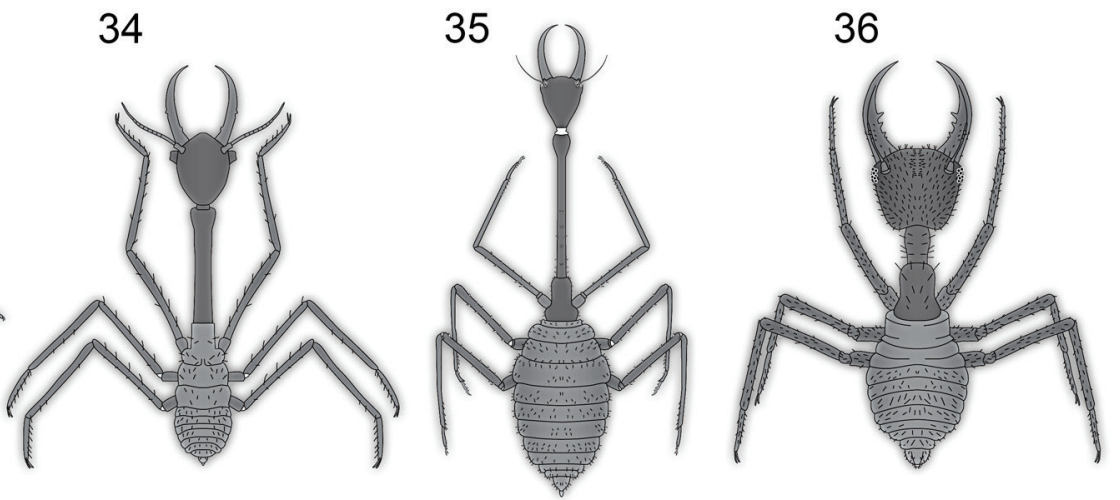

Figure 2. Larvae of thread-winged lacewings from the literature, continued. Numbers refer to specimen numbers in the text. $19-$ Tjederia namaquensis Mansell, 1977. •20-24 - Laurhervasia Navás, 1914. •20, 21 - Laurhervasia setacea (Klug). 22 - Laurhervasia rhodesiae Tjeder, 1967 . 23 - Laurhervasia transvaalensis Mansell, 1980. 24 - Laurhervasia namibica Mansell, 1980. 25 - Thysanocroce damarae (McLachlan, 1898). 26 , 27 - Concroce Tjeder, 1967. $\bullet 26$ - Concroce capensis Tjeder, 1967. 27 - Concroce walkeri Tjeder, 1967. 28 - Tjederia brevicornis Mansell, 1981. $\bullet$ 29 - Austrocroce mira (McKeown, 1939). 30 - Carnarviana cretata Mansell, 1983. 31 - Moranida peruviensis Mansell, $1983 . \cdot 32$ - Amerocroce boliviana Mansell, 1983. 33 - Veurise bruchi Navás, 1927a. •34, 35 - Necrophylus arenarius Roux, 1833. 36 - Josandreva sazi Navás, 1906. Drawings simplified from: 19 - Mansell (1977); 20-25 - Mansell (1980); 26, 27 - Mansell (1981a); 28 - Mansell (1981b); 29, 30 - Mansell (1983a); 31-33 - Mansell (1983b); 34, 35 - Monserrat (1983a); 36 - Monserrat (1983b). Drawings not to scale.

was provided as magnification factor, which does not provide a direct indication of size in the electronic versions, which were available to the authors.

Pierre (1952, fig. 24) also provided a drawing of a larva (specimen 14, Fig. 1) of Necrophylus arenarius Roux, 1833, labelled as "Pterocroce troglophilus Pierre". Pierre
(1952, fig. 25) additionally provided a drawing of a larva in a cocoon. Also here, size was provided as magnification factor, which does not provide a direct indication of size in the electronic versions, which were available to the authors. The drawing of the larva was re-figured by Tjeder (1967, fig. 1973), labelled "Pterocroce troglophilus 
Pierre". A simplified drawing was provided by HerreraFlórez et al. (2020b, fig. 5f).

18) MacLeod (1964) mentioned seven specimens in his possession, six long-necked ones, which he suggested to possibly represent Necrophylus arenarius Roux, 1833 (originally labelled as "Pterocroce storeyi"), and one short-necked one, which he suggested to possibly represent "?Croce filipennis". MacLeod (1964) depicted drawings of two specimens: 1) specimen 15 (Fig. 1) was labelled "Croce sp." (MacLeod 1964, figs 93, 94, 96). Length of head capsule, according to scale, was $0.72 \mathrm{~mm}$. 2) Specimen 16 (Fig. 1) was labelled "?Pterocroce storeyi" (MacLeod 1964, figs 97-99). Length of head capsule, according to scale, was $1 \mathrm{~mm}$.

19) Tjeder (1967) re-figured numerous specimens: specimen 5 (Tjeder 1967, fig. 1964) and specimen 6 (Tjeder 1967, fig. 1965), i.e. two drawings by Imms (1911), and specimen 9 (Tjeder 1967, fig. 1966), all labelled "Croce filipennis (Westwood)"; specimen 10 (Tjeder 1967, fig. 1967), labelled "Dielocroce joppana (Withycombe)"; specimen 11 (Tjeder 1967, fig. 1968), labelled "Pterocroce storeyi Withycombe", i.e. three drawings by Withycombe (1923), and also specimen 14 (Tjeder 1967, fig. 1973) labelled "Pterocroce troglophilus Pierre", i.e. a drawing by Pierre (1952). Tjeder (1967, fig. 1969) also re-figured a larva in a cocoon from Pierre (1952). Additionally, he provided some details of the neck region of a larva of Dielocroce sp. (Tjeder 1967, figs 1974-1977).

20) Riek (1970, fig. 29.12a) provided a drawing of a longnecked larva (specimen 17, Fig. 1) of a representative of Crocinae, possibly Necrophylus arenarius Roux, 1833. The specimen was labelled as "Nemopteridae". No indication of size was provided.

21) Mansell (1976, fig. 1) provided a drawing of a larva (specimen 18, Fig. 1) of Laurhervasia setacea (Klug, 1836). Length (including stylets), according to scale, was $8 \mathrm{~mm}$. Also numerous details were provided as SEM micrographs (Mansell 1976, figs 2-6).

22) Mansell (1977, fig. 9) provided a drawing of a larva (specimen 19, Fig. 2) of Tjederia namaquensis Mansell, 1977. Length (including stylets), according to scale, was $8.8 \mathrm{~mm}$. The drawing was re-figured by Monserrat (2008, fig. 11i), labelled "Tjederia".

23) Mansell (1980, fig. 3a, b) provided drawings of anterior body regions of two larval specimens (specimens 20 and 21, Fig. 2) of Laurhervasia setacea (Klug). Length of stylets + head + neck was, according to scale, $3.6 \mathrm{~mm}$ and $3.8 \mathrm{~mm}$ respectively; length of head capsule was in both specimens about $1 \mathrm{~mm}$.

Mansell (1980) furthermore provided drawings of a larva of Laurhervasia rhodesiae Tjeder, 1967 (Mansell 1980, fig. 4; specimen 22, Fig. 2) and a larva of Laurhervasia transvaalensis Mansell, 1980 (Mansell 1980, fig. 5; specimen 23, Fig. 2). Specimen 22 measured (total length, including stylets) $6.4 \mathrm{~mm}$ according to scale, specimen 23 measured $7 \mathrm{~mm}$. The latter drawing was re-figured by Monserrat (2008, fig. 11h), labelled as "Laurhervasia".

Finally, Mansell (1980) provided drawings of a larva of Laurhervasia namibica Mansell, 1980 (Mansell 1980, fig. 9; specimen 24, Fig. 2) and a larva of Thysanocroce damarae (McLachlan, 1898) (Mansell 1980, fig. 10; specimen 25, Fig. 2). Specimen 24 measured (total length, including stylets) $6.7 \mathrm{~mm}$ according to scale, specimen 25 measured $6.1 \mathrm{~mm}$. The latter drawing was re-figured by Monserrat (2008, fig. 11f), labelled "Thysanocroce".

24) Mansell (1981a, fig. 2) provided a drawing of a larva (specimen 26, Fig. 2) of Concroce capensis Tjeder, 1967. Total length (including stylets) according to scale was about $5.3 \mathrm{~mm}$. Mansell (1981a, fig. 3) also provided a drawing of a larva (specimen 27, Fig. 2) of Concroce walkeri Tjeder, 1967. Total length (including stylets) according to scale was about $6.6 \mathrm{~mm}$. The drawing was re-figured by Monserrat (2008, fig. 11e), labelled as "Concroce".

25) Mansell (1981b, fig. 3) provided a drawing of a larva (specimen 28, Fig. 2) of Tjederia brevicornis Mansell, 1981. Total length (including stylets) according to scale was about $7.3 \mathrm{~mm}$. A strongly simplified scheme based on this specimen was provided by Haug et al. (2019a, figs 3 and 4).

26) Mansell (1983a, fig. 53) provided a drawing of a larva (specimen 29, Fig. 2) of Austrocroce mira (McKeown, 1939). Total length (including stylets) according to scale was about $5.4 \mathrm{~mm}$. The drawing was re-figured by New (1989, fig. 148 b) labelled "Austrocroce mira (shortnecked Crocinae)" and Monserrat (2008, fig. 11c), labelled "Austrocroce".

Mansell (1983a, fig. 54) also provided a drawing of a larva (specimen 30, Fig. 2) of Carnarviana cretata Mansell, 1983. Total length (including stylets) according to scale was about $5.5 \mathrm{~mm}$. The drawing was re-figured by New (1991, fig. 34.12a) labelled "Austrocroce sp." and Monserrat (2008, fig. 11d), labelled "Carnarviana".

27) Mansell (1983b, fig. 14) provided a drawing of a larva (specimen 31, Fig. 2) of Moranida peruviensis Mansell, 1983. Total length (including stylets) according 
to scale was about $7.8 \mathrm{~mm}$. The drawing was re-figured by New (1989, fig. 148 c) labelled "Moranida peruviensis (long-necked Crocinae)" and Monserrat (2008, fig. 11k), labelled as "Moranida".

Mansell (1983b, fig. 15) also provided a drawing of a larva (specimen 32, Fig. 2) of Amerocroce boliviana Mansell, 1983. Total length (including stylets) according to scale was about $7.6 \mathrm{~mm}$. The drawing was re-figured by Monserrat (2008, fig. 11j), labelled as "Amerocroce".

Mansell (1983b, fig. 25) provided a drawing of a larva (specimen 33, Fig. 2) of Veurise bruchi Navás, 1927a. Total length (including stylets) according to scale was about $6.3 \mathrm{~mm}$. The drawing was re-figured by Monserrat (2008, fig. 11g), labelled as "Veurise".

28) Monserrat (1983a) provided drawings of larvae of Necrophylus arenarius Roux, 1833, all labelled "Pterocroce capillaris". Monserrat (1983a, fig. 4) depicted a first stage larva (specimen 34, Fig. 2), as well as some details of the egg and the hatching process (Monserrat 1983a, figs 1-3). A simplified drawing was provided by HerreraFlórez et al. (2020b, fig. 5b). Total length (including stylets) according to scale was about $2.15 \mathrm{~mm}$.

He also provided a drawing of a later stage (3?) larva (Monserrat 1983a, fig. 5; specimen 35, Fig. 2), as well as numerous details of the larva (Monserrat 1983a, figs 6-16). Total length (including stylets) according to scale was about $9.1 \mathrm{~mm}$. The anterior region of the drawing of the entire larva was re-figured in Gepp (1984, fig. 18b). The entire drawing was re-figured by Monserrat (2008, fig. 111), labelled as "Necrophylus $=($ Pterocroce $)$ ", and Monserrat et al. (2012, fig. 6a), labelled as "Necrophylus arenarius Roux, 1833”.

29) Monserrat (1983b, fig. 2) provided a drawing of a stage 1 larva (specimen 36, Fig. 2) of Josandreva sazi Navás, 1906. Additionally, numerous details were provided (Monserrat 1983b, figs 1, 3a-d, 4, 5). Total length (including stylets) according to scale was about $1.7 \mathrm{~mm}$.

Monserrat (1983b, fig. 6) also provided a drawing of a stage 2 larva (specimen 37, Fig. 3) of the same species. Also here numerous additional details were provided (Monserrat 1983b, figs 7-11). Total length (including stylets) according to scale was about $5.5 \mathrm{~mm}$.

Furthermore, Monserrat (1983b, fig. 12) provided a drawing of a stage 3 larva (specimen 38, Fig. 3 ) of the same species. Total length (including stylets) according to scale was about $6.3 \mathrm{~mm}$. Additionally, close-ups on setae on various body regions were provided (Monserrat 1983b, figs 13a-e, 14). The drawing of the larva was re-figured by Monserrat (2008, fig. 11a), labelled as "Josandreva", and Monserrat et al. (2012, fig. 6b), labelled "Josandreva sazi Navás, 1906".
30) Miller \& Stange (1989) provided micrographs of a larva (specimen 39, Fig. 3) of Moranida manselli Miller \& Stange, 1989 in dorsal (Miller \& Stange 1989, fig. 1) and ventral view (Miller \& Stange 1989, fig. 2). Additionally, a close-up on the anterior region was provided (Miller \& Stange 1989, fig. 3). No indication of size was provided. Drawings based on the photographs in dorsal and ventral view were depicted in Heckman (2017, fig. 2.30) labelled "Moranida manselli".

31) New (1989, fig. 148 b) re-figured specimen 29 [labelled "Austrocroce mira (short-necked Crocinae)"], i.e. the drawing of Austrocroce mira by Mansell (1983a). Mansell (1983a, fig. 148 c) also re-figured specimen 31 [labelled "Moranida peruviensis (long-necked Crocinae)"], i.e. the drawing of Moranida peruviensis by Mansell (1983b).

32) New (1991, fig. 34.12a) re-figured specimen 30 (labelled as "Austrocroce sp."), i.e. the drawing of Carnarviana cretata by Mansell (1983a, fig. 54).

33) Tröger (1993, abb. 2) re-figured specimen 2, i.e. the drawing by Schaum (1857), labelled as "Necrophilus arenarius Roux".

34) Aspöck \& Aspöck (1999) figured two specimens. They provided a micrograph of a larva (specimen 40, Fig. 3) of Laurhervasia setacea (Klug, 1836) (Aspöck \& Aspöck 1999, Abb. 53). The image was originally shot by Peter Duelli. Size was given as $5 \mathrm{~mm}$. The image was refigured by Grimaldi \& Engel (2005, fig. 9.17). Grimaldi \& Engel (2005, fig. 54) also provided a micrograph of a larva (specimen 41, Fig. 3) of Necrophylus arenarius Roux, 1833, labelled as "Pterocroce capillaris (Klug)". A simplified drawing was provided by Herrera-Flórez et al. (2020b, fig. 5g). Size was given as $9 \mathrm{~mm}$.

35) Hölzel (1999, fig. 4) provided a drawing of a larva (specimen 42, Fig. 3) of Necrophylus arenarius Roux, 1833, labelled as "Pterocroce capillaris (Klug, 1836)". A simplified drawing was provided by Herrera-Flórez et al. (2020b, fig. 5e). No indication of size was provided.

36) Grimaldi \& Engel (2005, fig. 9.17) re-figured specimen 40, i.e. the micrograph of Laurhervasia setacea (Klug, 1836) from Aspöck \& Aspöck (1999, fig. 53).

37) Suludere et al. (2006, fig. 7) provided a micrograph of a larva (specimen 43, Fig. 3) of Dielocroce baudii (Griffini, 1895). Total length (including stylets) according to scale was about $2.8 \mathrm{~mm}$. Additionally, a micrograph of the egg (Suludere et al. 2006, fig. 1), numerous SEM closeups of the egg (Suludere et al. 2006, figs 2-6) and also of the larva (Suludere et al. 2006, figs 8-17) were provided. 
38) Aspöck \& Aspöck (2007, fig. 38) provided a micrograph of a larva (specimen 44, Fig. 3) of Tjederia namaquensis Mansell, 1977. The photograph was provided by Peter Duelli. Size was given as $5 \mathrm{~mm}$.

39) Satar et al. (2007, fig. 7) provided a micrograph of a larva (specimen 45, Fig. 3) of Croce schmidti (Navás, 1927b) in dorsal view. Additionally, SEM images were provided, an overview in latero-dorsal view (Satar et al. 2007, fig. 8), as well as numerous close-ups (Satar et al. 2007, figs 9-14). Only the micrograph is considered, as it remains unclear whether the SEM overview was taken from the same specimen or not, yet this seems likely. Only the SEM micrograph is provided with a scale. Total length (including stylets) according to this scale is slightly less than $1 \mathrm{~mm}$. The image was re-figured by Monserrat (2008, fig. 9f), labelled "Croce schmidti". A simplified drawing of the specimen was provided by Haug et al. (2019a, fig. 4).

40) Monserrat (2008, fig. 9f) re-figured specimen 45, i.e. the micrograph of Croce schmidti (Navás, 1927b) by Satar et al. (2007, fig. 7), labelled "Croce schmidti".

Monserrat (2008, fig. 9i) also provided a micrograph of a stage 3 larva (specimen 46, Fig. 3) of Necrophylus arenarius Roux, 1833. No indication of size was provided.

Additionally, Monserrat (2008, fig. 9j) provided a micrograph of a larva (specimen 47, Fig. 3) of Laurhervasia setacea (Klug, 1836). Also close-ups of anterior region (Monserrat 2008, fig. 9k) and head (Monserrat 2008, fig. 9l) were depicted. No indication of size was given.

Monserrat (2008) furthermore provided several incomplete specimens of larvae of Dielocroce hebraea Hölzel, 1975, including a quite complete head (Monserrat 2008, fig. 10a; specimen 48, Fig. 3), incomplete head capsules (Monserrat 2008, figs 10b-d) and an exuvium (Monserrat 2008, fig. 10g; specimen 49, Fig. 3) as well as a close-up on the head of the latter (Monserrat 2008, fig. 10h). No indications of size were provided.

Monserrat (2008) also re-figured numerous specimens: specimen 38 (Monserrat 2008, fig. 11a; drawing by Monserrat 1983b), labelled "Josandreva"; specimen 6 (Monserrat 2008, fig. 11b; drawing by Imms 1911), labelled "Croce"; specimen 29 (Monserrat 2008, fig. 11c; drawing by Mansell 1983a), labelled "Austrocroce"; specimen 30 (Monserrat 2008, fig. 11d; drawing by Mansell 1983a), labelled "Carnarviana"; specimen 27 (Monserrat 2008, fig. 11e; drawing by Mansell 1981a), labelled "Concroce"; specimen 25 (Monserrat 2008, fig. 11f; drawing by Mansell 1980), labelled "Thysanocroce"; specimen 33 (Monserrat 2008, fig. 11g; drawing by Mansell 1983b), labelled "Veurise"; specimen 23 (Monserrat 2008, fig. 11h; drawing by Mansell 1980), labelled "Laurhervasia"; specimen 19 (Monserrat 2008, fig. 11i; drawing by Mansell 1977), labelled "Tjederia"; specimen 32
(Monserrat 2008, fig. 11j; drawing by Mansell 1983b), labelled "Amerocroce"; specimen 31 (Monserrat 2008, fig. 11k; drawing by Mansell 1983b), labelled "Moranida"; specimen 35 (Monserrat 2008, fig. 111; drawing by Monserrat 1983a), labelled "Necrophylus = $($ Pterocroce $)$ "; specimen 10 (Monserrat 2008, fig. $11 \mathrm{ma}$; drawing by Withycombe 1923), labelled "Dielocroce"; specimen 11 (Monserrat 2008, fig. $11 \mathrm{mb}$; drawing by Withycombe 1923), labelled "Necrophylus = (Pterocroce)"; specimen 12 (Monserrat 2008, fig. $11 \mathrm{mc}$; drawing by Withycombe 1923), labelled "Necrophylus $=($ Pterocroce $)$ ".

41) Monserrat et al. (2012) re-figured specimen 34 (Monserrat et al. 2012, fig 6a), i.e. a drawing by Monserrat (1983a), labelled as "Necrophylus arenarius Roux, 1833" and specimen 38 (Monserrat et al. 2012, fig. 6b), i.e. a drawing by Monserrat (1983b) labelled "Josandreva sazi Navás, 1906".

42) Aspöck \& Aspöck (2014, fig. middle left on page 25) provided a micrograph of a larva (specimen 50, Fig. 3) of Necrophylus arenarius Roux, 1833, labelled "Pterocroce". No indication of size was provided.

43) Tusun \& Satar (2016) provided micrographs of a larva (specimen 51, Fig. 3) of Dielocroce ephemera (Gerstaecker, 1894). Additionally, Tusun \& Satar (2016) provided numerous details of the larva with SEM images (figs 3-18). Head was stated to measure $0.35 \mathrm{~mm}$.

44) Heckman (2017, fig. 2.30) re-figured specimen 39, i.e. images of Miller \& Stange (1989), but as drawings, labelled "Moranida manselli".

45) Badano et al. (2017, fig. 1c) figured two specimens of Necrophylus arenarius Roux, 1833, labelled as "Pterocroce capillaris (Klug)", showing intraspecific predation. The specimens are shown in a slightly oblique angle and in front of a sandy background, providing only little contrast against the bodies, which is natural due to a certain camouflaging effect. We can therefore not reliably redraw these specimens and cannot further consider them here.

46) Badano et al. (2018, fig. 1d) provided a micrograph of a larva (specimen 52, Fig. 3) of Necrophylus arenarius Roux, 1833, labelled as "Pterocroce capillaris (Klug)". Another micrograph shows a larva in lateral view (Badano et al. 2018, fig. 2). It is unclear whether it is the same specimen as in the other figure (Badano et al. 2018, fig. 1d) and therefore not further considered here. They also depict details of head and neck (Badano et al. 2018, fig. 6a), possibly of the same specimen. A simplified drawing was provided by Herrera-Flórez et al. (2020b, fig. 52c). No indication of size was provided. 

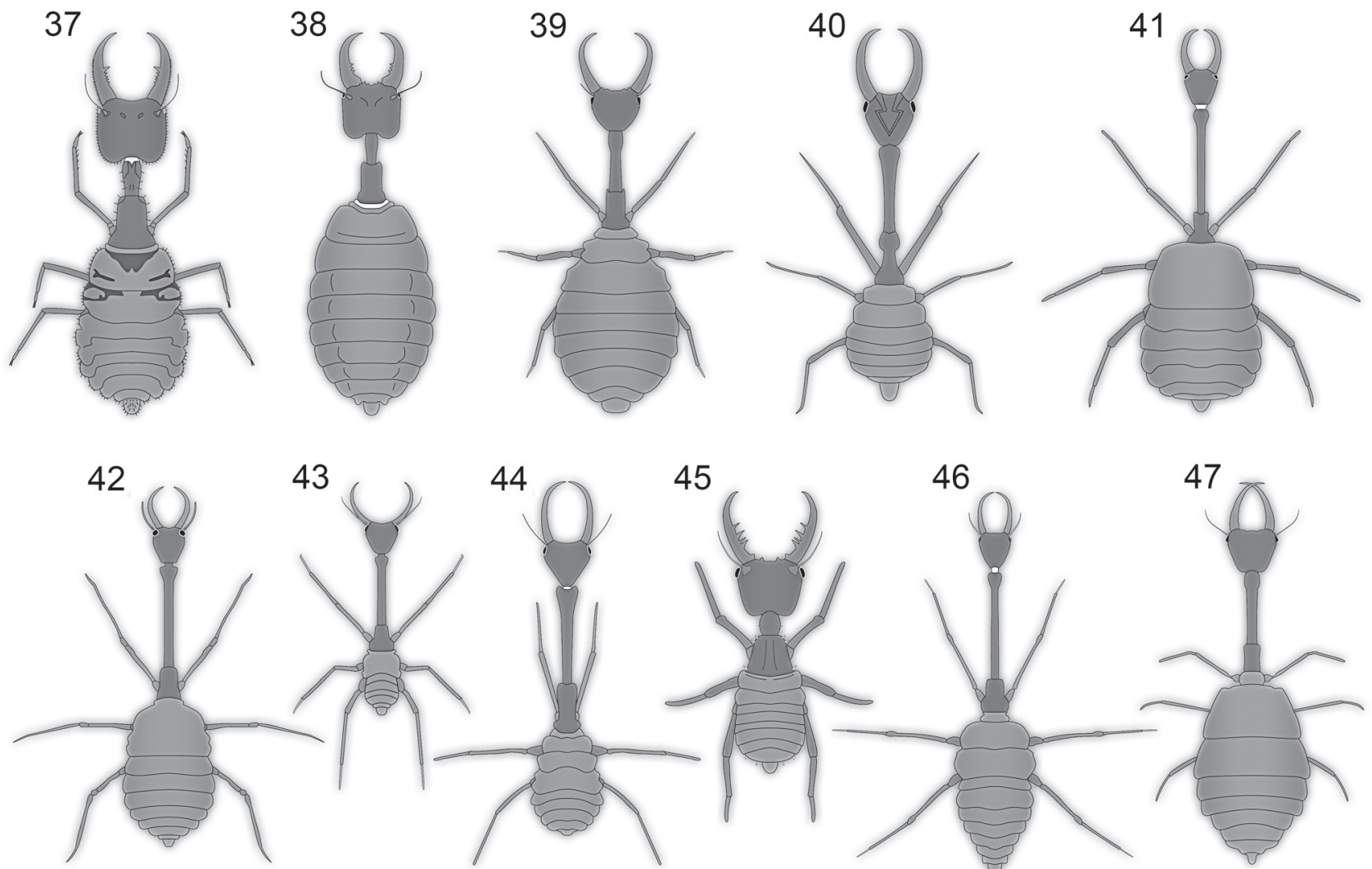

43

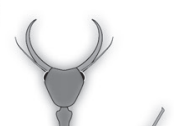

44

45

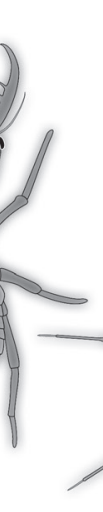

46

47

48

49

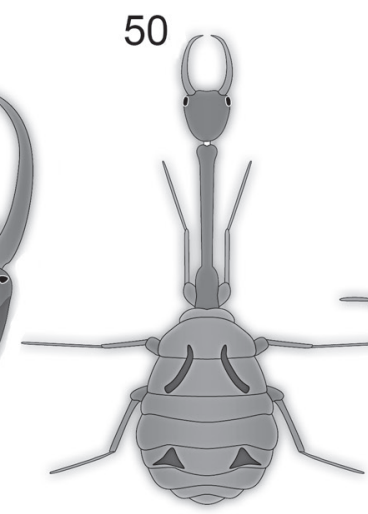

50

51

51
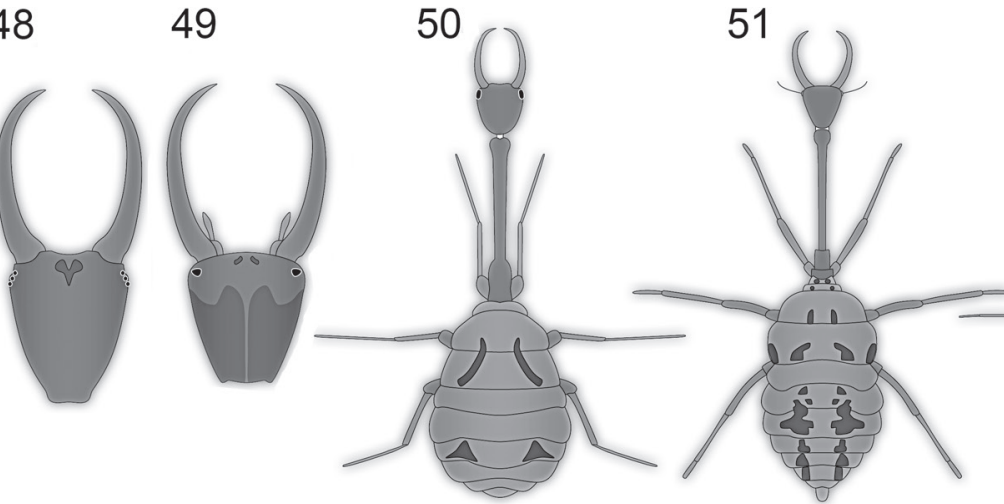

52
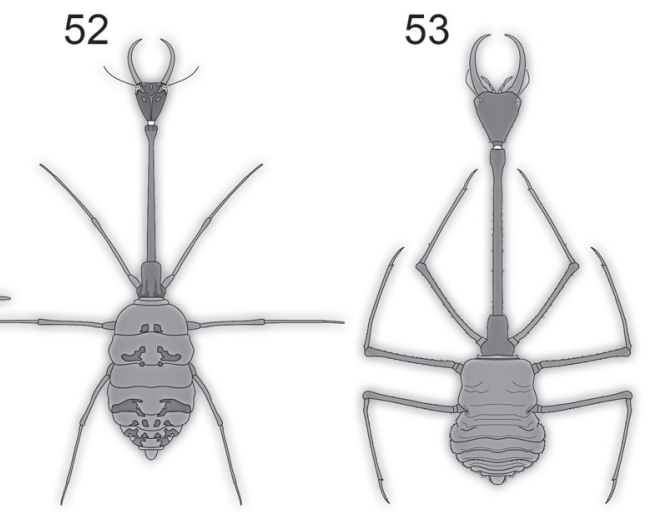

Figure 3. Larvae of thread-winged lacewings from the literature, continued. Numbers refer to specimen numbers in the text. $-37,38-$ Josandreva sazi Navás, 1906. 39 - Moranida manselli Miller \& Stange, 1989. 40, 47 - Laurhervasia setacea (Klug, 1836). 41, 42, 46, 50, 52 - Necrophylus arenarius Roux, 1833. 43 - Dielocroce baudii (Griffini, 1895). 44 - Tjederia namaquensis Mansell, 1977. • 45 - Croce schmidti (Navás, 1927b). 48, 49 - Dielocroce hebraea Hölzel, 1975. • 51 - Dielocroce ephemera (Gerstaecker, 1894). 53 - Necrophylus sp. Drawings simplified from: 37,38 Monserrat (1983b); 39 - Miller \& Stange (1989); 40, 41 - Aspöck \& Aspöck (1999); 42 - Hölzel (1999); 43 - Suludere et al. (2006); 44 - Aspöck \& Aspöck (2007); 45 - Satar et al. (2007); 46-49 - Monserrat (2008); 50 - Aspöck \& Aspöck (2014); 51 - Tusun \& Satar (2016); 52 - Badano et al. (2018); 53 - Herrera-Flórez et al. (2020b). Drawings not to scale.

47) Herrera-Flórez et al. (2020b) provided micrographs (Herrera-Flórez et al. 2020b, figs. 2, 3) and a drawing (Herrera-Flórez et al. 2020b, fig. 5a) of a larva (specimen 53, Fig. 3) of Necrophylus sp. Total length (including stylets) according to scale was $8.7 \mathrm{~mm}$. The authors suggested that the larva was a stage 2 specimen. They also provided simplified versions based on sev- eral specimens of Necrophylus arenarius Roux, 1833, specimen 34 (Herrera-Flórez et al. 2020b, fig. 5b), i.e. a drawing by Monserrat (1983a); specimen 52 (HerreraFlórez et al. 2020b, fig. 5c), i.e. a drawing by the authors; specimen 1 (Herrera-Flórez et al. 2020b, fig. 5d), i.e. the drawing by Roux (1833); specimen 42 (Herrera-Flórez et al. 2020b, fig. 5e), i.e. the drawing by Hölzel (1999); 
specimen 14 (Herrera-Flórez et al. 2020b, fig. 5f), i.e. a drawing by Pierre (1952); specimen 41 (Herrera-Flórez et al. 2020b, fig. 5g), i.e. an image by Aspöck \& Aspöck (1999).

\section{Fossil larvae with long necks}

As above, all occurrences are listed chronologically. Also, re-figured cases are included chronologically despite the redundancy (see above).

48) Xia et al. (2015) figured four specimens of lacewing larvae with long necks. All are preserved in amber from Myanmar, also known as Burmese amber. We could not find any hint to a scale or length on the pages related to the specimens, but we cannot fully exclude that we might have overlooked such information in other parts of the book as the text is entirely in Chinese.

Specimen 54 (Xia et al. 2015, upper fig. on page 99; Fig. 4) appears rather complete. It is depicted in dorsolateral view. The stylets are therefore more difficult to view, but appear to bear five teeth each. As the specimen is seen laterally, it could not be further considered here for shape analysis.

Specimen 55 (Xia et al. 2015, lower fig. on page 99; Fig. 4) is less complete. Parts of thorax and the entire abdomen are missing. The preserved part is accessible in dorsal view. Each stylet bears four teeth.

Specimen 56 (Xia et al. 2015, upper fig. on page 100; Fig. 4) is rather complete, only the legs are not well accessible. It is accessible in dorsal view. Each stylet bears ten teeth.

Specimen 57 (Xia et al. 2015, upper fig. on page 100; Fig. 4) is rather complete, only the legs are not well access- ible. It is depicted in slightly lateral view. Each stylet bears four teeth.

49) Zhang (2017) figured three specimens of lacewing larvae with long necks. All are preserved in amber from Myanmar, also known as Burmese amber. We could not find any hint to a scale or length on the pages related to the specimens, but we cannot fully exclude that we might have overlooked such information in other parts of the book as the text is in Chinese.

Specimen 58 (Zhang 2017, fig. on page 400; Fig. 4) appears rather complete. It is depicted in dorsal view. Each stylet bears nine teeth. A close up of the head is also provided (Zhang 2017, fig. on page 401).

Specimen 59 (Zhang 2017, upper fig. on page 402; Fig. 4) also appears rather complete. It is accessible in dorsal view. Each stylet bears four teeth.

Specimen 60 (Zhang 2017, upper fig. on page 402; Fig. 4) appears rather complete, yet the terminal end is outside the field of view. It is depicted in dorsal view. Each stylet bears four teeth.

50) Haug et al. (2019a) provided several micrographs and details of a fossil lacewing larva with a long neck (Haug et al. 2019a, figs 1,2; specimen 61; Fig. 4), as well as simplified drawings (Haug et al. 2019a, fig. 3a) and a more detailed restoration (Haug et al. 2019a, fig. 4). The specimen measured $6.75 \mathrm{~mm}$. Each stylet bears three teeth. They also provided a drawing based on specimen 45 (Haug et al. 2019a, also in fig. 4), i.e. the larva of Croce schmidti (Navás, 1927b) by Satar et al. (2007, fig. 7), but referencing to the re-figuring of Monserrat (2008, fig. 9f). Satar et al. (2007, figs 3 and 4) additionally provided a simplified version of specimen 28 , i.e. larva of Tjederia brevicornis Mansell, 1981 by Mansell (1981b).
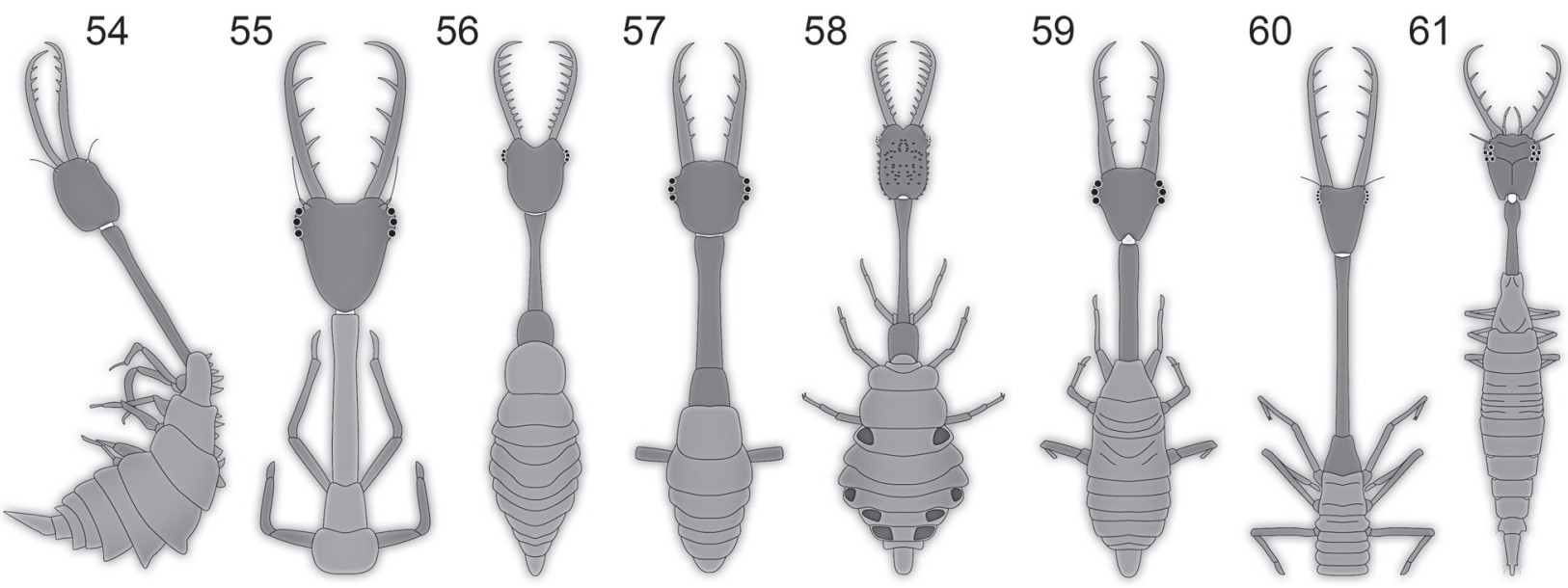

Figure 4. Fossil lacewing larvae with long necks from the literature. Numbers refer to specimen numbers in the text. Drawings simplified from: 54-57 - Xia et al. (2015); 58-60 - Zhang (2017); 61 - Haug et al. (2019a; SMNS BU-340). Drawings not to scale. 


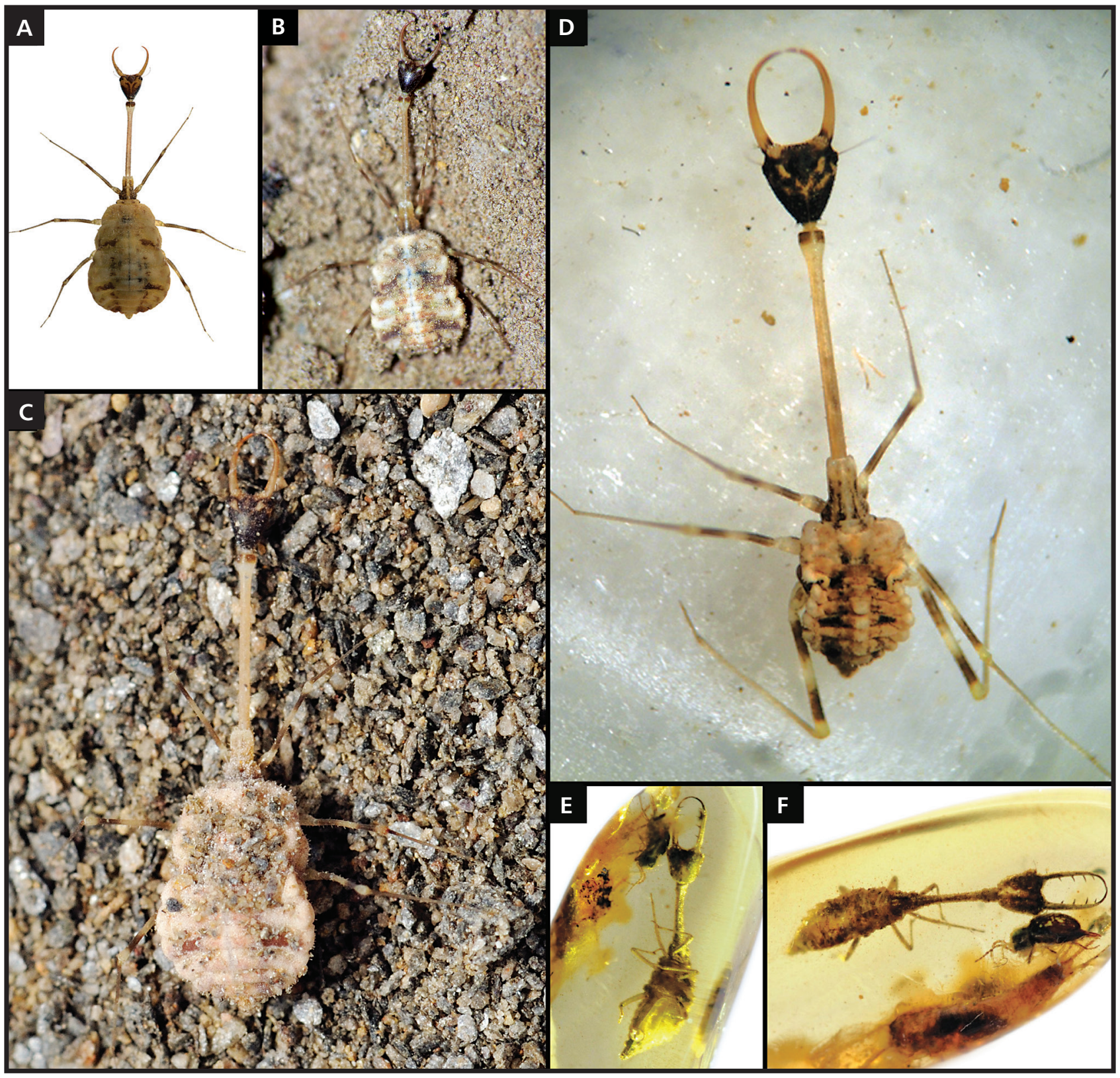

Figure 5. Additional larvae of thread-winged lacewings and a fossil lacewing larva with long neck. • A, D - Dielocroce hebraea Hölzel, 1975; A specimen 62; D - specimen 65, image kindly provided by Asadolla Hosseini Chegeni. • B, C. Necrophylus arenarius Roux, 1833; B - specimen 63, image kindly provided by Ana Rita Gonçalves; C - specimen 64, image kindly provided by Adrià Miralles. • E, F. - fossil larva with long neck (specimen 66), images kindly provided by www.fossilmall.com; E - ventral view; F - dorsal view. Images not to scale.

\section{Additional extant larvae of Crocinae}

Given the relative rarity of larvae of Crocinae in the literature, we amended our dataset with images taken by colleagues and hobby photographers that have documented such larvae out in the field. Such type of data is comparable to numerous published specimens such as specimens $40,41,44$, or 50 . We have used images from photography repositories in comparable studies (Haug \&
Haug 2019) and consider such images as a valuable amendment.

51) A larval specimen of Dielocroce hebraea Hölzel, 1975 (specimen 62, Fig. 5A) was photographed by one of the authors $(\mathrm{GW})$. The specimen was photographed alive, the measured body length is $8.2 \mathrm{~mm}$.

52) A larval specimen of Necrophylus arenarius Roux, 
1833 was photographed by Ana Rita Gonçalves (specimen 63, Fig. 5B). The specimen was photographed alive in the field, no direct indication of size is available.

53) A larval specimen of Necrophylus arenarius Roux, 1833 was photographed by Adrià Miralles (specimen 64, Fig. 5C). The specimen was photographed alive in the field, no direct indication of size is available.

54) A larval specimen of supposedly Dielocroce hebraea Hölzel, 1975 was photographed by Asadolla Hosseini Chegeni (specimen 65, Fig. 5D). The specimen was photographed alive, no direct indication of size is available.

\section{Additional fossil larvae with long necks}

Fossil representatives of long-necked lacewing larvae are even rarer than their modern counterparts. We therefore expand the data set by several specimens, partly from nonpublic collections. Of these specimens, only the outlines are considered for analysis. Hence the data availability is comparable to the case of modern specimens photographed in the field. Some of the specimens could be acquired for public collections. All specimens are preserved in 100 million years old amber from Myanmar ("Burmese amber").

55) Photographs of one larval lacewing specimen with a long neck were provided by the team from $w w w$. fossilmall.com (specimen 66, Fig. 5E, F). The specimen measured about $11 \mathrm{~mm}$. Each stylet bears four teeth. There are two apparent syn-inclusions: a smaller one, possibly a beetle, and a more prominent one, a jumping bristletail.

56) Specimen BUB 1803 is part of the collection of one of the authors (specimen 67, Fig. 6A, B). The specimen has a total length of $2.94 \mathrm{~mm}$. Each stylet bears ten teeth.

57) Specimen BUB 1804 is part of the collection of one of the authors (specimen 68, Fig. 6C, D). The specimen has a total length of $2.68 \mathrm{~mm}$. Each stylet bears eight teeth.

58) Specimen PED 0085 (specimen 69, Fig. 7) is part of the collection of the Palaeo-Evo-Devo (PED) Research Group, Ludwig-Maximilians-Universität München (LMU Munich), Germany. The specimen has a total length of $10.17 \mathrm{~mm}$. Each stylet bears four teeth.

59) Specimen PED 0250 (specimen 70, Fig. 8) is part of the collection of the Palaeo-Evo-Devo (PED) Research Group, Ludwig-Maximilians-Universität München (LMU
Munich), Germany. The specimen has a total length of $7.76 \mathrm{~mm}$. Each stylet bears eight teeth.

\section{Shape analysis}

Mandible. - Principal component 1 (PC1) explains 70.4\% of the overall shape variation (Suppl. Text 1). It is dominated by aspects of the curvature, shape of the distal tip and, to a certain degree, by the presence of teeth along the median edge. A low value represents a proximally straight and only distally curved mandible, with a rather strong tip and teeth in the distal region of the mandible. A medium value represents a mandible that is more curved, tapering towards the tip and lacking teeth. A high value is not represented in the true data set; hence this shape is not explored (Suppl. Fig. 6).

Principal component 2 (PC2) explains $9.9 \%$ of the overall shape variance (Suppl. Text 1). It is dominated by the shape of the distal tip and presence of teeth along the median edge. A low value represents a mandible with teeth and a thinner tip. A medium high value represents a mandible without teeth and a somewhat thicker tip. A high value represents a mandible with teeth and a rather massive tip (Suppl. Fig. 6).

The first two principal components explain more than $80 \%$ of the overall shape variance. Further PCs are not explored here, as their influence is relatively low. All PC scores are given in the supplement (Suppl. Tab. 2).

Head. - Principal component 1 (PC1) explains $40 \%$ of the overall shape variation (Suppl. Text 2). It is dominated by aspects of the head capsule shape on the anterior end. A low value represents a heart-shaped head, while the high value represents a rather square-shaped head (Suppl. Fig. 7).

Principal component 2 (PC2) explains $22.5 \%$ of the overall variation (Suppl. Text 2). It is dominated by the head capsule shape on the posterior end. Low values represent a mostly rectangular head with widened occipital area, while high values represent a mostly triangular head, with the triangle facing anteriorly (Suppl. Fig. 7).

The relatively low proportion of the variation explained by these two principal components can be explained by the complex and varying shape of the head capsule. All PC scores are given in the supplement (Suppl. Tab. 3).

Neck. - Principal component 1 (PC1) explains $94.3 \%$ of the overall shape variation (Suppl. Text 3). It is dominated by aspects of the neck width. A low value represents a narrow neck, while a high value represents a broader, more square-shaped neck (Suppl. Fig. 8).

Principal component 2 (PC2) explains $2.3 \%$ of the overall variation (Suppl. Text 3 ). It is dominated by the neck 


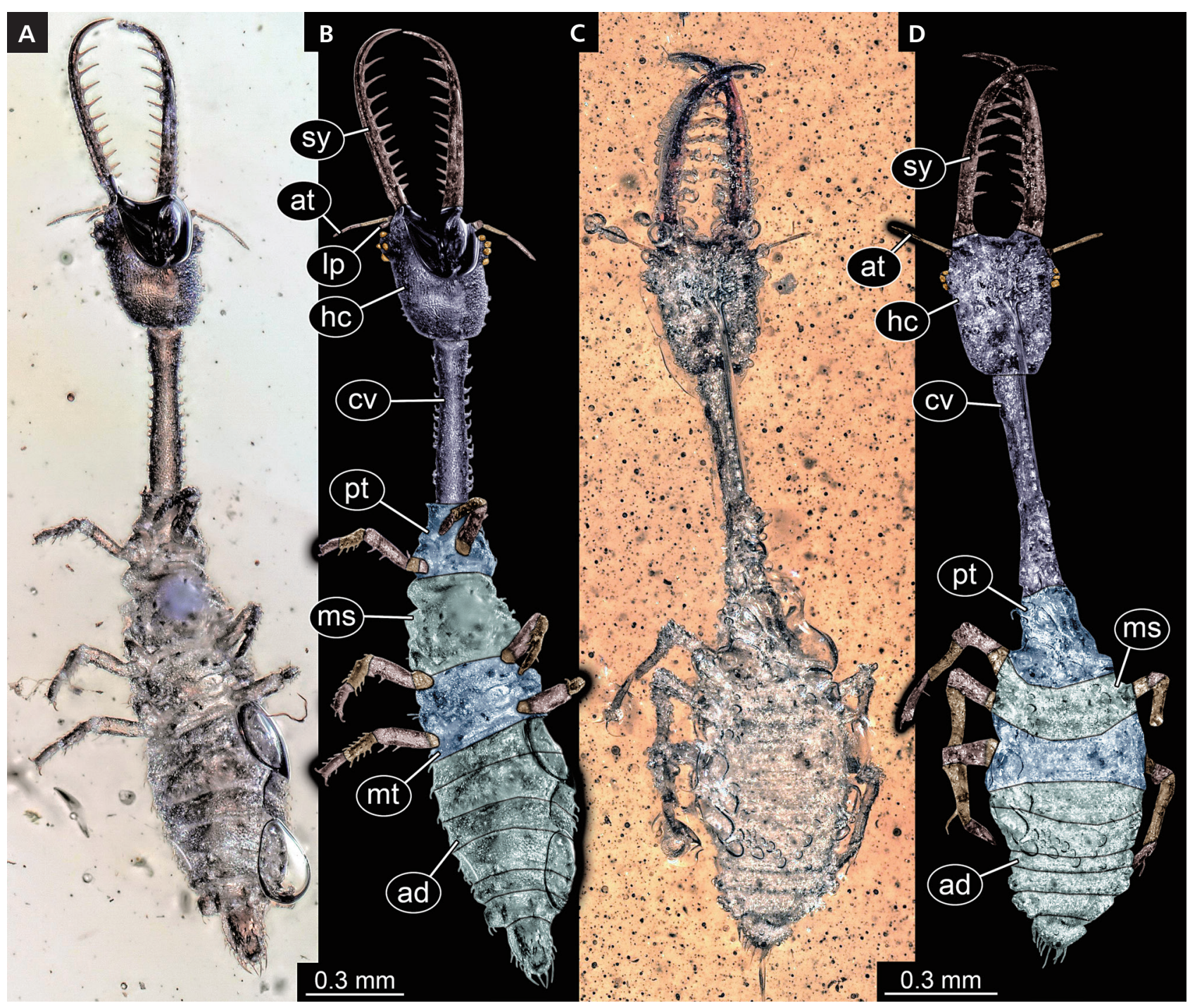

Figure 6. New fossil lacewing larvae with long necks. A, B - specimen 67 (BUB 1803); A - composite image; B - colour-marked version of A. C, D - specimen 68 (BUB 1804); C - composite image; D - colour-marked version of C. Abbreviations: ad - abdomen; at - antenna; cv - cervix (sclerotised part of neck); hc - head capsule; lp - labial palp; ms - mesothorax; $\mathrm{mt}$ - metathorax; pt - prothorax; sy - stylet.

shape at its ends. Low values represent a neck with wide rear end, while high values represent a mostly spindleshaped neck which widens at the middle (Suppl. Fig. 8).

The first two principal components explain more than $95 \%$ of the overall shape variance. Further PCs are not explored here, as their influence is relatively low. All PC scores are given in the supplement (Suppl. Tab. 3).

Trunk. - Principal component 1 (PC1) explains $73.3 \%$ of the overall shape variation (Suppl. Text 4). It is dominated by aspects of the trunk at the posterior end. A low value represents a spindle-shaped trunk. High values represent a trunk with narrow anterior end and very wide posterior end (Suppl. Fig. 9).

Principal component 2 (PC2) explains $8.7 \%$ of the overall variation (Suppl. Text 4). It is dominated by the presence or absence of a narrower anterior region. Low values indicate the absence of such a region (i.e. the trunk is simply spindle-shaped), while high values indicate the presence of a distinct, narrow anterior region (Suppl. Fig. 9).

The first two principal components explain more than $80 \%$ of the overall shape variance. Further PCs are not explored here, as their influence is relatively low. All PC scores are given in the supplement (Suppl. Tab. 3).

Total shape. - Principal component 1 (PC1) explains $64.9 \%$ of the overall shape variation (Suppl. Text 5). It is dominated by aspects of the abdomen width. A low value represents a body with a rounded abdomen. High values represent a body with elongated, oval abdomen (Suppl. Fig. 10). 
Principal component 2 (PC2) explains $22.3 \%$ of the overall variation (Suppl. Text 5). It is dominated by the general width of the body. Low values represent a wide head on a wide body, while high values represent a narrow head on the narrow body (Suppl. Fig. 10).

The first two principal components explain more than $80 \%$ of the overall shape variance. Further PCs are not explored here, as their influence is relatively low. All PC scores are given in the supplement (Suppl. Tab. 3).

\section{Scatter plots}

The different scatter plots of the principal components describing the shapes of various structures reveal re- occurring patterns: 1) the modern larvae can be roughly differentiated into the long-neck types and the shortneck types in most plots; 2) the fossil long-necked larvae differ in many aspects from the modern ones. In more details:

Mandible. - The truly long-necked larvae (Necrophylus, Dielocroce) cluster very tightly together (Fig. 9A). A single exception is the larva of Dielocroce berlandi depicted by Pierre (1952; specimen 13 in Fig. 1; see also further below). Also the larvae with moderately long necks (Tjederia, Thysanocroce, Laurhervasia, Amerocroce, Moranida) cluster together with long necked forms. Even some of the larvae with short necks cluster here, yet most of these \{ Concroce-Croce group: Concroce +

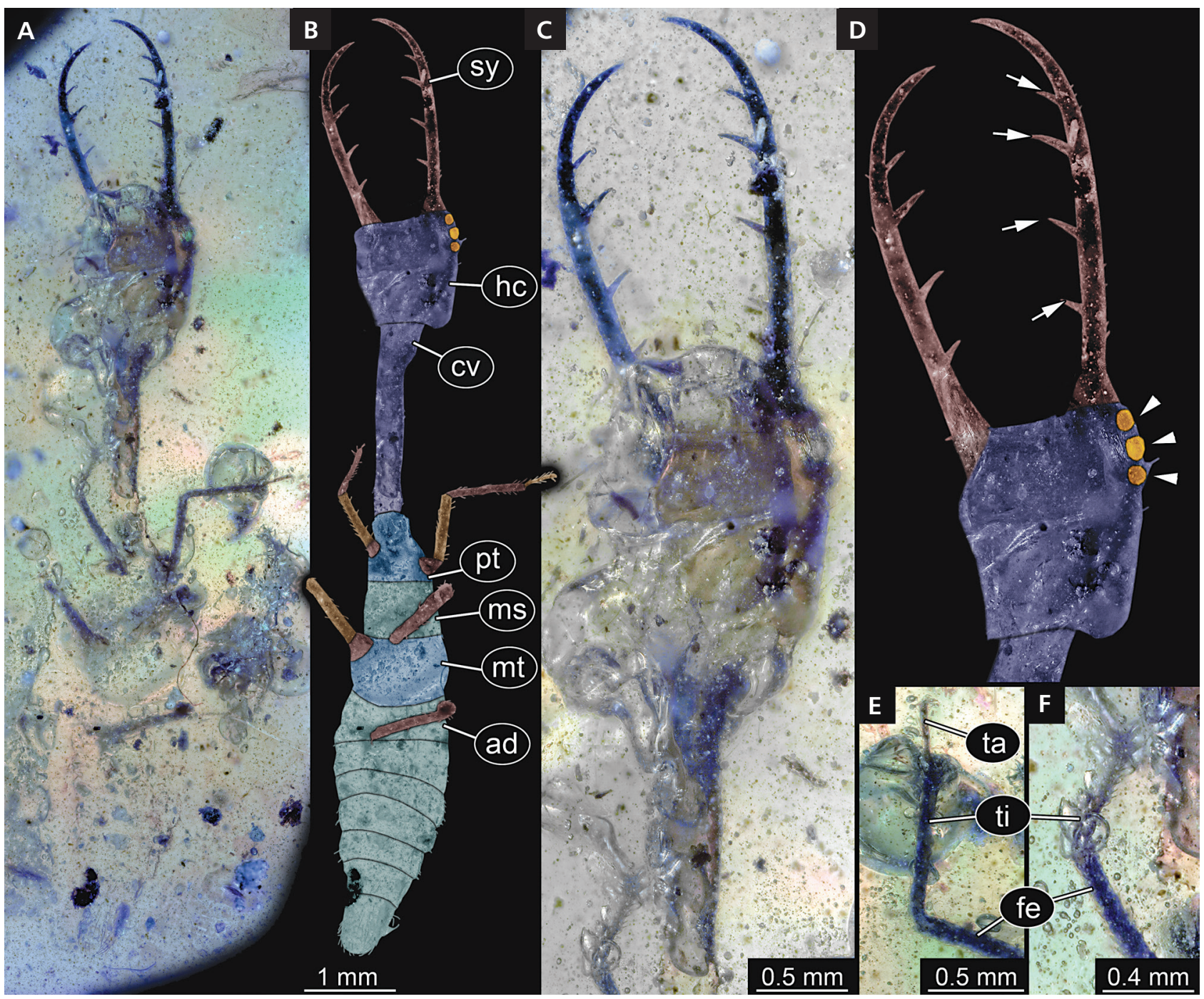

Figure 7. New fossil lacewing larvae with long necks, continued. Specimen 69 (PED 0085). A - composite image; B - colour-marked version of A; $\mathrm{C}$ - close-up on head; D - colour-marked version of right side of C, note arrows indicating teeth and arrow heads marking stemmata; E, F - close-up on locomotory appendages (walking legs). Abbreviations: ad - abdomen; cv - cervix (sclerotised part of neck); fe - femur; hc - head capsule; ms mesothorax; $\mathrm{mt}$ - metathorax; $\mathrm{pt}$ - prothorax; sy - stylet; ta - tarsus; ti - tibia. 


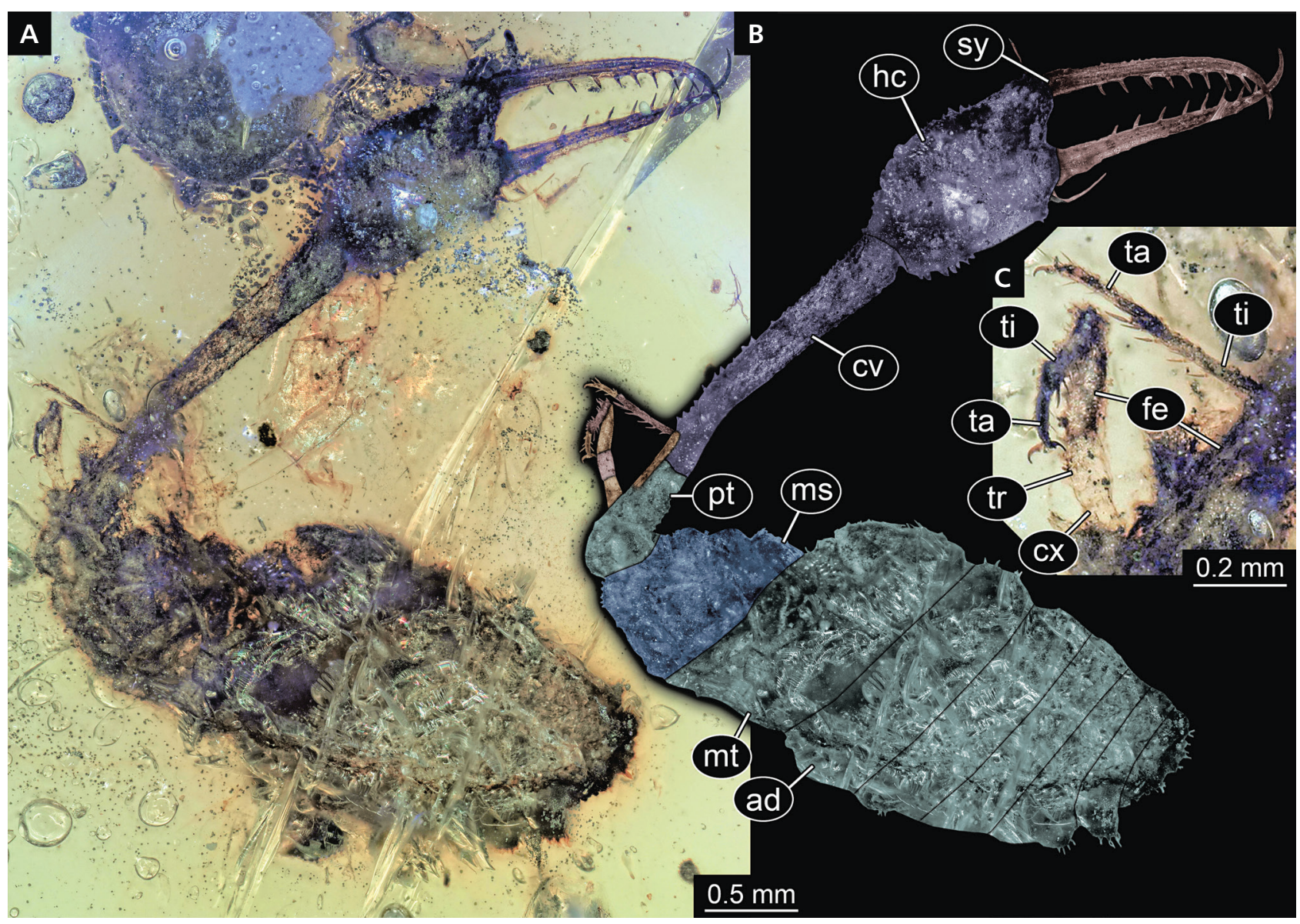

Figure 8. New fossil lacewing larvae with long necks, continued. Specimen 70 (PED 0250). A - composite image; B - colour-marked version of A; $\mathrm{C}$ - close-up on locomotory appendages (walking legs). Abbreviations: ad - abdomen; cv - cervix (sclerotised part of neck); cx - coxa; fe - femur; hc - head capsule; ms - mesothorax; mt - metathorax; $\mathrm{pt}$ - prothorax; sy - stylet; ta - tarsus; ti - tibia; $\operatorname{tr}$ - trochanter.

$[($ Austrocroce + Carnarviana $)+($ Josandreva + Croce $)]\}$ are widely distributed in the upper middle to upper left area of the morphospace, indicating a higher variability in the mandible shape. The tight cluster represents mandibles without teeth that are gently curved and quite slender. The more widely distributed data points represent more massive mandibles with small teeth (often also termed pseudo-teeth, e.g. Lu et al. 2019; yet we feel unable to reliably make this distinction).

The area occupied by fossil larvae has very little overlap with the area occupied by modern forms (Fig. 9A). The fossils combine rather slender overall shape with numerous prominent teeth. Fossil larvae occupy more or less two separate areas. Most plot in the middle left area rather close to the modern short-necked larvae. One of the modern larvae plots among these fossils. It is one of the larvae of Croce fillipennis depicted by Ghosh (1910; specimen 4 in Fig. 1). The mandibles appear here very thin, quite unlike other depictions of larvae of the same species. Therefore, it seems possible that the drawing of this larva by Ghosh (1910) is an artistic deviation rather than reflecting a true morphology. This interpretation would mean that although there are modern larvae with teeth in the mandibles, the mandibles still differ considerably from those of the fossils. This is especially true for the other fossil larvae which plot far lower left. The fossil larvae closer to the modern forms have only few teeth, the ones plotting lower left have a high number of still prominent teeth.

Head. - For the shape of the head the separation into two groups is very apparent (Fig. 9B). The heads on the left side of the plot are more triangular, while the ones on the right side are more square-shaped. The short-necked larvae plot in the right side of the morphospace, the modern longnecked forms and the fossils plot in the left side. Only the one larva of Dielocroce berlandi (Pierre 1952; specimen 13 in Fig. 1) plots among the short-necked forms.

The larvae with intermediate necks plot separately. Some plot with the long-necked forms, others with the short-necked ones. This means that we basically lack intermediate forms here. One fossil also plots on the right side, yet it is one of the more difficult to interpret ones 

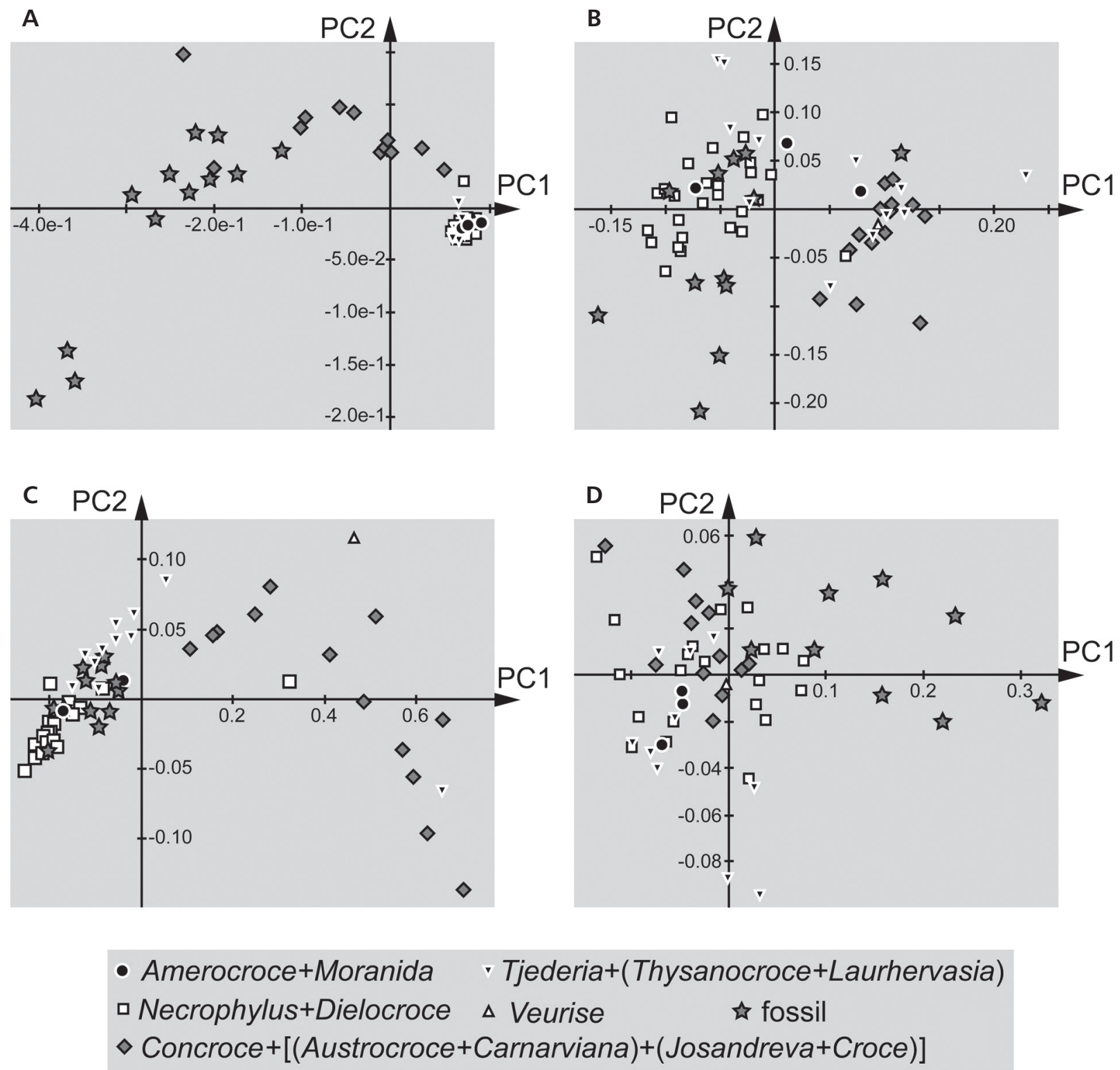

Figure 9. Scatter plots of the principal components (PCs) 1 and 2 of different morphological structures. A - mandible; B - head; C - neck; D - trunk.

(Xia et al. 2015; specimen 57), as it is preserved slightly obliquely. It remains therefore partly unclear whether the head of this specimen is actually more square-shaped.

Neck. - The shape of the neck also allows to separate two distinct groups (Fig. 9C). The larvae plotting in the left part of the morphospace are the long-necked forms (Necrophylus, Dielocroce), the ones with intermediate necks, and the fossil ones. They all cluster tightly around a straight line, indicating that shape aspects represented by $\mathrm{PC} 1$ and $\mathrm{PC} 2$ are strictly correlated in these larvae. Among the long-necked forms only the larva of Dielocroce berlandi (Pierre 1952; specimen 13 in Fig. 1) plots, as in other shapes, with the short-necked larvae. Among the larvae with intermediate necks, that of Thysanocroce damarae (Mansell 1980; specimen 25 in Fig. 2) plots among the short-necked forms. Indeed, the neck is rather short.

Trunk. -The shape of the trunk does not allow to separate distinct sub-groups among the modern larvae (Fig. 9D). Also some of the fossils plot close to the modern larvae, yet most of them plot clearly away from the modern ones, indicating that most of the fossil larvae have quite a different body shape. The shape of the trunk is less well suited for shape analysis as it is strongly dependent on the ontogenetic stage and how well the animal is fed. Hence even within the same species and within the same stage 

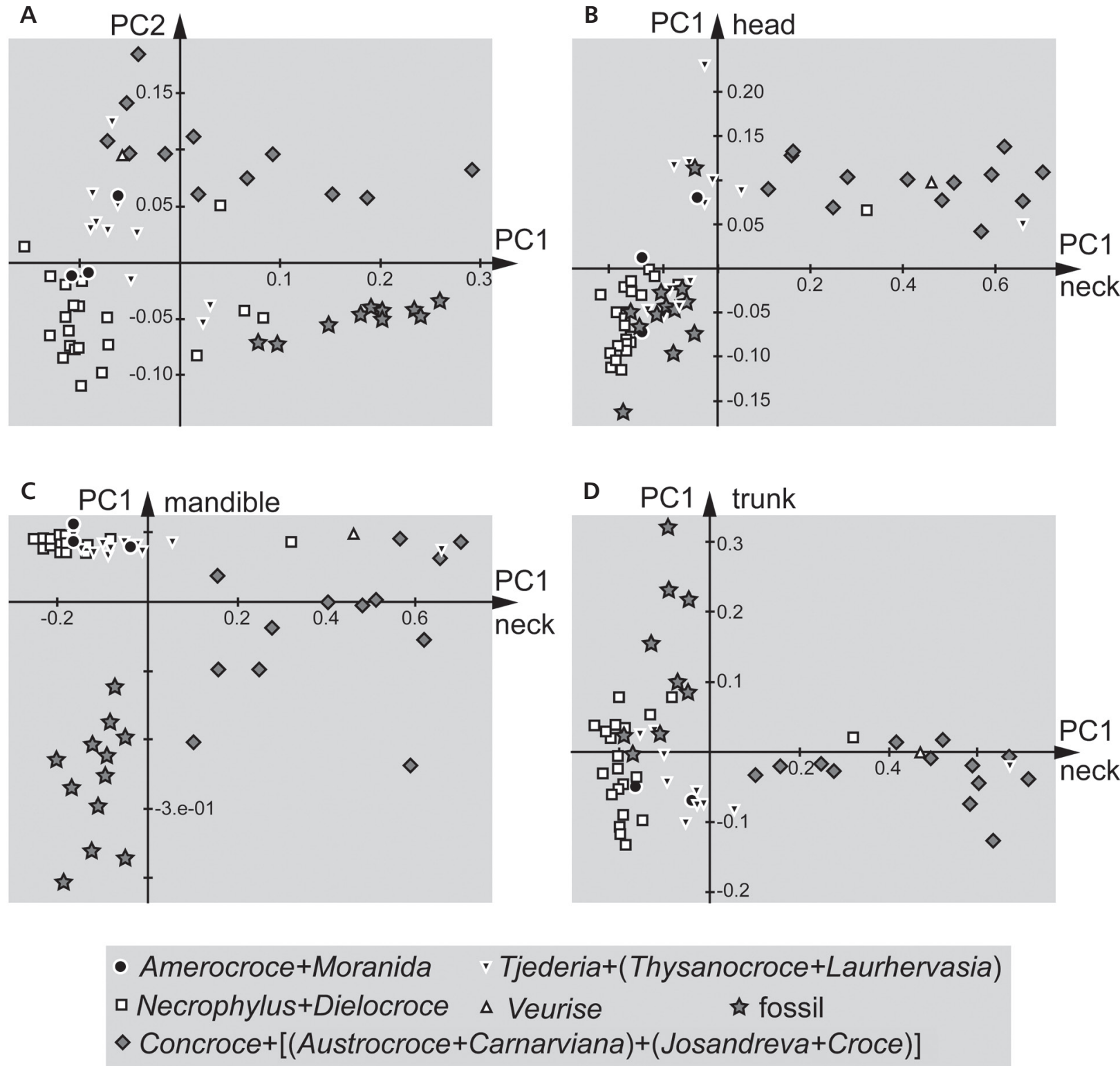

Figure 10. Scatter plots of the principal components (PCs) of different morphological structures, continued. A - total body; B - head vs. neck; C mandible $v s$. neck; D - trunk vs. neck.

we can expect quite variability here. Still, the trunk shape reveals a rather principle difference between the modern forms and the fossil ones.

Total body. - The shape of the entire body separates the long-necked forms well from the short-necked forms (Fig. 10A; again, except for the larva of Dielocroce berlandi; Pierre 1952; specimen 13 in Fig. 1). The larvae with intermediate necks plot in between the two other groups, partly overlapping with them. Only two of the fossil larvae plot close to some of the long-necked and intermediate forms. Most fossil larvae separate well from all modern ones plotting in the lower right of the morphospace.
Head vs. neck. - Two very distinct groups can be separated (Fig. 10B). In the lower left the long-necked larvae form a rather tight cluster together with most fossil larvae and one part of the larvae with intermediate necks, although, as above, the larva of Thysanocroce damarae (Mansell 1980; specimen 25 in Fig. 2) plots strongly separated, deep among the short-necked larvae. The other not so tight cluster is formed by the short-necked larvae, the remaining larvae with intermediate necks, the larva of Dielocroce berlandi (Pierre 1952; specimen 13 in Fig. 1), and a single fossil larva (Xia et al. 2015; specimen 57), which again is the one that is more challenging to interpret. 

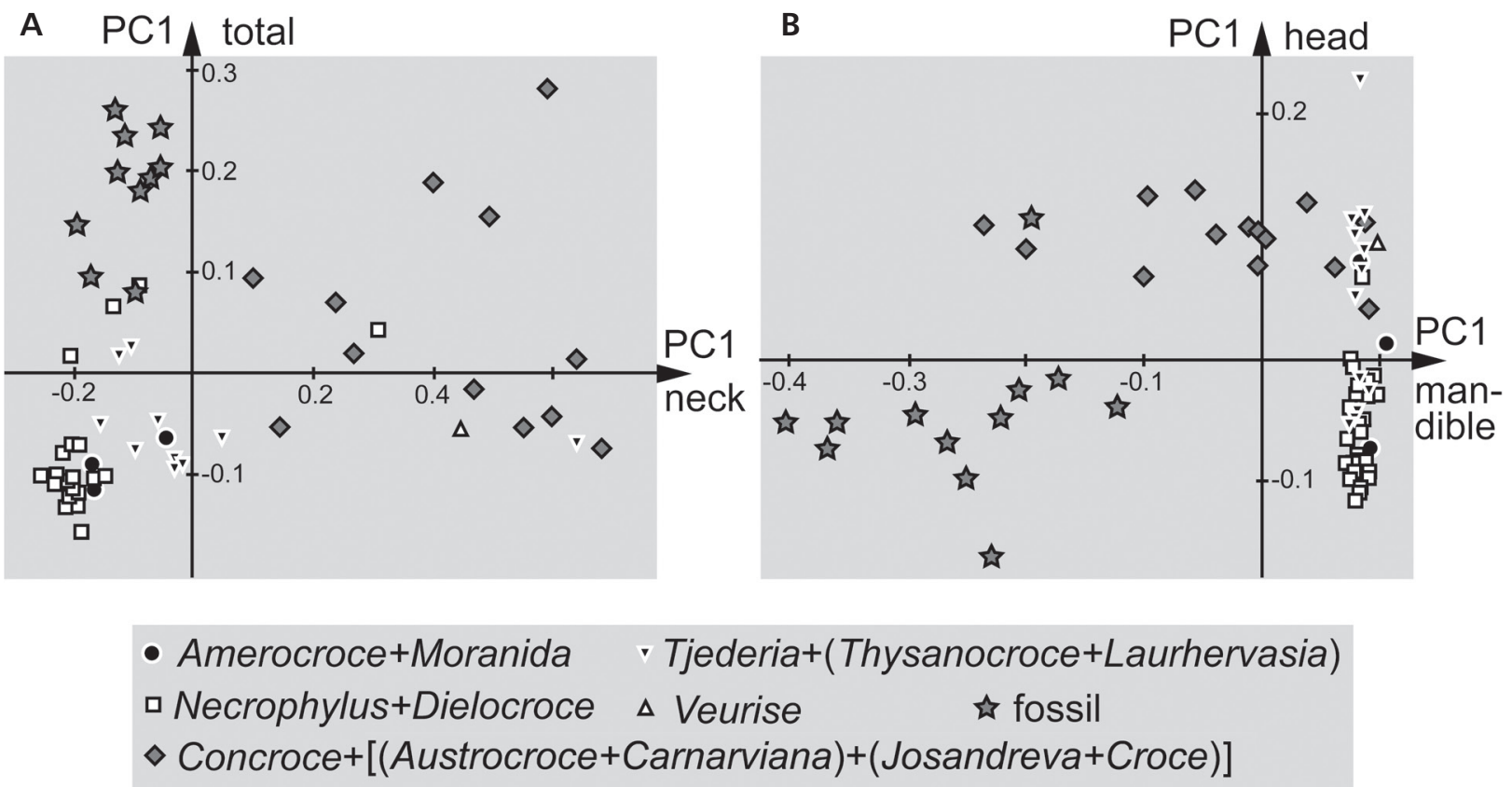

Figure 11. Scatter plots of the principal components (PCs) of different morphological structures, continued. A - total body vs. neck; B - head vs. mandible.

Mandible vs. neck. - There are three quite distinct groups apparent in this scatter plot (Fig. 10C). In the upper left a very tight cluster is formed by the modern long-necked larvae and those with intermediate necks. On the right side, more loosely, the short-necked forms (Concroce-Croce group) plot again together with the larva of Dielocroce berlandi (Pierre 1952; specimen 13 in Fig. 1) and Thysanocroce damarae (Mansell 1980; specimen 25 in Fig. 2). The fossil larvae form a separate cluster in the lower left.

Trunk vs. neck. - The overall occupied area is strongly L-shaped (Fig. 10D). In the lower right, the short-necked forms plot (together with the larva of Dielocroce berlandi; Pierre 1952; specimen 13 in Fig. 1; and Thysanocroce damarae; Mansell 1980; specimen 25 in Fig. 2). In the lower left, the long-necked larvae and those with intermediate necks plot. In the upper left, the fossil larvae plot.

Total vs. neck. - The plot largely resembles that of trunk vs. neck, yet with more variance along the y-axis (Fig. 11A).

Head vs. mandible. - The modern forms plot in a distinct L-shape, quite well separating long-necked larvae plotting along a vertical line and the short-necked forms along a horizontal line (Fig. 11B). The larvae with intermediate necks partly overlap with both. The L-shaped area occupied by the modern larvae is in the right part of the morphospace, with the corner of the L in the upper right part. The fossil larvae plot distinctly separate in the lower left.

\section{Discussion}

\section{General coarser phylogenetic frame}

According to the phylogeny of Lu et al. (2019), Veurise is the sister group to all other groups within Crocinae, the Concroce-Croce group being the sister group to all the rest. This indicates that the ancestral larva of Crocinae had a rather short neck, a more square-shaped head and more massive mandibles. This is congruent with the morphology of larvae of the sister group of Crocinae, Nemopterinae, as they all have this principle morphology. Larvae of Nemopterinae additionally have small teeth in the mandibles, comparable to larvae of the ConcroceCroce group. This indicates that the presence of teeth is likely an ancestral feature; the absence in larvae of Veurise is a novelty and a convergence to the group Necrophylus + Dielocroce.

The size of the teeth already became smaller in the lineage towards the, unfortunately unnamed, group $\{$ Tjederia $+($ Thysanocroce + Laurhervasia $)+[($ Amerocroce + Moranida $)+($ Necrophylus + Dielocroce $)]\}$. The reduction of teeth size seems to be also coupled to ontogeny, the teeth in first stage larvae are more pronounced (see also discussion in Haug et al. 2019a).

Concerning the fossils, the situation is still complicated. Lu et al. (2019) considered the fossil long-necked larvae as larvae of Nemopteridae (as also Xia et al. 2015, Zhang 2017). Makarkin et al. (2017) suggested that these 
larvae were those of highly specialised antlion-like forms of Araripeneuridae.

Haug et al. (2019a) provided the first detailed account on a long-necked fossil larva and discussed the possible phylogenetic position of such larvae. They pointed out that the larvae may indeed be considered as larvae of Crocinae, yet then we need to assume that several characters must have evolved convergently. Another possible interpretation is that they are closer to the early lineage of Myrmeleontiformia; in this case, the long neck would need to be considered a convergence. Also in other lineages of Neuroptera, e.g. in Nevrorthidae, the larvae have rather elongate neck regions (recently reviewed in Haug et al. $2020 \mathrm{~b}$ ). Yet, on the other hand, the similarities of modern long-necked larvae of Crocinae and the fossil larvae include also the very narrow and slim morphology not seen in other lineages. Unfortunately, our new observations, as well as the phylogenetic frame discussed above, do not improve this situation significantly, but may give some hints.

Our quantitative approach further supports the notions by Haug et al. (2019a) that the fossil larvae are quite different from modern larvae of Crocinae, especially in the combination of morphological aspects as not occurring today ("Chimera"). In this respect, it will be important to also consider some of the other peculiar fossil lacewing larvae in the future. It is planned to further increase the frame for the analysis. The larvae of the Superfang-type (Haug et al. 2019b) and related forms (Badano et al. 2018) might be especially considered. The long-necked larvae with a higher number of teeth especially resemble these other larvae in this aspect and in the overall mandible shape. For example, the strongly L-shaped occupied area in the morphospace trunk $v s$. neck (Fig. 10D) might be seen as indicating a certain "impossible" morphology in the unoccupied area. Yet, exactly this area might be well filled by the Superfang-type larvae.

However, at least some of the Superfang-like forms differ from the long-necked larvae in possessing empodia. Although we cannot see the distal tips of the locomotory appendages in all fossil long-necked larvae (e.g. the one from Haug et al. 2019a), at least in those where they are accessible, there seem to be no empodia.

Still, presence of empodia is likely a rather ancestral feature, being secondarily lost in numerous lineages. Also for Myrmeleontiformia, we must assume the presence of empodia as apparent in larvae of Psychopsidae (see Haug et al. 2020a and references therein for a recent summary). Absence of empodia in at least some of the long-necked larvae gives a weak signal that they could indeed be closer related to, or even are representatives of Crocinae. If they are interpreted as representatives of an early branch of Myrmeleontiformia, we would need to assume an independent loss of the empodia. Yet, this remains a weak argument as empodia have been lost repeatedly in numerous lineages.

\section{Phylogenetic interpretation of some specific larvae}

The pattern of the larva of Dielocroce berlandi (Pierre 1952; specimen 13 in Fig. 1) repeatedly plotting strongly separated from other larvae of the group Necroyphylus + Dielocroce indicates that this larva might indeed not be a representative of Dielocroce. The species was originally described based on the larval specimen and later reinterpreted as an ingroup of Dielocroce. Hence, we have no direct correlation further supporting the idea that this larva is indeed a representative of the group Necrophylus + Dielocroce. Neck shape, head shape and mandible shape (with a tooth!) are clearly very different from all other larvae of this group. Therefore, we see it as more likely that this specimen is not the larva of a species of Dielocroce, but of a species either closer related to the Concroce-Croce group, or even an ingroup of the latter.

Also the larva of Thysanocroce damarae (Mansell 1980; specimen 25 in Fig. 2) is very different from supposedly closely related forms. It remains unclear whether the three specimens mentioned by Mansell (1980) were bred from eggs, or how they were associated with the supposed adults. Hence, it is not completely unlikely that the systematic interpretation of specimen 25 is incorrect as well, but it seems less likely than in the case of specimen 13 (see above). If the interpretation of specimen 25 as larva of Thysanocroce damarae is correct, and also the close relationship of Thysanocroce, Tjederia and Laurhervasia is correct, this has severe consequences: We need to assume that we see significant evolutionary reversals in the larval morphology of Thysanocroce, as this larva shows so many traits otherwise seen in Veurise and the ConcroceCroce group, indicating that these are plesiomorphic traits for the latter two. Yet, for Thysanocroce this would then represent an apomorphic condition. Already Mansell (1980) had noted this significant difference.

\section{Life styles and morphology: the long-necked forms}

Especially the long-necked larvae appear to be rather restricted in their morphology. In other words, having a long neck appears to demand for a certain morphology of the head and the mandibles. This indicates that there is a certain functional coupling, most likely as an adaptation to a specific life style.

We have a rather good idea how these long-necked forms hunt for prey from field and lab observations on 
larvae of two Dielocroce species made by one of the authors (GW). The larvae live in caves or shaded rock notches, or under rock shelves overhanging thick patches of dry dusty clay. They take advantage of the fine clay substrate for camouflage by burrowing into it in a backwards movement. The long neck accounts for greater head manoeuvrability and assists in the burrowing action by moving clay particles to cover the tracks of the larva. Because a bite to the abdomen can cause a fatal injury, the larva often scans the burrowing area with its head to ensure it is not already taken by another larva. Larvae are often seen fighting over a burrowing spot, suggesting that they are somewhat territorial; therefore, they try to avoid conflict by examining the area before burrowing. The long-necked larvae are sit-and-wait predators that wait under the fine substrate in ambush for passing arthropods. The larvae share their habitat with sand cockroaches, silverfish, and ants, but also venomous assassin bugs and spiders. When a potential prey of the right size walks over the larvae, it swiftly emerges from the substrate, impales it with its sickle-shaped jaws and injects it with venom. The long neck allows the larva to keep its distance and avoid contact with a struggling prey that can damage the soft abdomen of the larva.

\section{Life styles and morphology: the short-necked forms and intermediates}

The morphological structures appear less confined in short-necked forms, yet also here the neck shape appears to have a certain coupling to a certain type of mandible morphology and head shape.

It is interesting to note that the forms with intermediate necks do only rarely occupy an area in between the longnecked and short-necked forms (e.g. Fig. 10A). More often they separate rather distinctly into two sub-groups, of which one clusters closely to the long-necked forms and the other closely to the short-necked ones (e.g. Figs $9 \mathrm{~B}, 10 \mathrm{~B})$. This supports that there is a certain functional coupling between neck shape, head shape and mandible shape and only certain areas of the morphospace represent functional (adaptive?) morphologies.

\section{Life styles and morphology: the fossils}

The fossil long-necked forms differ in their morphology and especially in the combination of certain features, leading them to plot in certain morphospaces quite apart from all the modern forms. The fossil forms clearly demonstrate that the seeming coupling indicated by looking at the extant forms cannot be strictly functional or evolutionary, as some of the fossils indeed combine an elongate neck with a quite different mandible morphology. Yet, the seeming stricter coupling in modern forms might be related to their specific life habits. The difference between modern and fossil forms clearly indicates that they had quite different life styles.

This should not come as a surprise. All modern larvae of Crocinae live in rather arid regions. At least the longnecked forms spend their time partly buried in the sand. This is not a good habitat for being preserved in amber. Especially organisms living closer to the trees possibly producing resin as well as a rather close association to water seems to be advantageous for preservation in amber.

The long-necked fossil larvae ("Chimera-type larvae") appear to be not very rare. We have considered 13 specimens here, more have been seen by the authors offered by various traders. We can therefore assume that these larvae indeed had a certain affinity to habitats in which they had a chance to be rather regularly preserved in amber. Hence, already the fact that these larvae are present in ambers indicates a quite different life style for the fossil larvae. It also explains the (so far) absence of fossils resembling the modern larvae of Crocinae to a higher degree, possibly indicating a similar life style.

Also the fossils show quite a diversity of shape of mandibles, already recognisable by the two rather distinct subtypes; if simply comparing the occupied areas, it seems at least as large as the area occupied by the extant ones, although there are comparably few specimens. Hence, we should also expect a certain diversity of lifestyles in the fossil forms.

For an easier reference, we suggest to restrict the expression 'Chimera-type larvae' to the fossil larvae with only few teeth, as these have mandibles resembling those of Ascalaphidae. We suggest to use the nick name 'Decadent-larva' for those with numerous teeth as at least some of them (specimens 56,67) indeed possess ten teeth ("deca" meaning ten, "dent" meaning tooth).

\section{Assessing the diversity of long-necked lacewing larvae}

For other ingroups of Myrmeleontiformia, we can quite directly compare modern representatives with their fossil counterparts. Larvae of silky lacewings (Psychopsidae) seem not to have changed their habitat since the Cretaceous, and so we have several larvae in the Cretaceous, but also in the Eocene, as well as in the modern fauna (Haug et al. 2020a). Likewise, we find numerous forms resembling modern larvae of owlflies (Ascalaphidae) in Cretaceous, Eocene and also Miocene ambers (MacLeod 1970, Weitschat \& Wichard 2002, Wang et al. 2016, Badano et al. 2018, Herrera-Flórez et al. 2020a). In the case of 
Psychopsidae we know in fact many more fossil larvae than larvae in the modern fauna (Haug et al. 2020a).

For Crocinae the case is different. For most lacewing groups we know the larvae of about $10 \%$ of the species (cf. Gepp 1984). In Crocinae we know significantly more than that. On the other hand, the fossils seem to be rarer than in some of the other groups. Also, it appears that modern larvae of Crocinae are restricted to habitats not easily preserving fossils. We therefore could have had such larvae back in the Cretaceous, but simply have no record of them. There is so far a single adult of Crocinae in amber from Myanmar (Lu et al. 2019) and it appears to be a representative of an early diverged group, sister to all modern forms; hence phylogenetic bracketing (Witmer 1995) cannot be used to suggest that this species had larvae similar to those of the modern forms. Indeed, it cannot be fully excluded that one of the long-necked fossil larvae is a larval form of this species.

The fossil larvae apparently had morphologies and most likely also ecologies no longer represented in the modern fauna. As we have found these larvae so far exclusively in amber from Myanmar, but not in any younger amber, we need to assume that these forms have become extinct possibly already in, or at the end of the Cretaceous.

Given this situation, we can make only limited statements about the changes in diversity of long-necked lacewing larvae:

1) We cannot exclude that part of the morphologies and occupied habitats remained stable, as we cannot expect to find larvae with modern type morphologies in the fossil record.

2) We can recognise that there was a morphology, and most likely ecology, represented by fossil long-necked larvae that became extinct.

3) Due to statement 1), it remains unclear whether there was a shift from tree-associated habitats (as indicated by the fossil larvae) to a more arid habitat.

4) While we can recognise a loss of diversity (under statement 2), it remains unclear, due to the systematic uncertainties of the fossil larvae, whether this loss indeed concerns Crocinae; it definitely represents a decline of diversity of Myrmeleontiformia.

5) Although typologically we can only roughly distinguish two types of fossil larvae (many teeth, few teeth), the quantitative shape analysis indicates that even these two already represent quite varying morphologies, although less diverse than the morphologies of the modern-day Crocinae larvae. Yet, given the rather unequal sample sizes we did not apply sample size correction, which might indeed reveal a relatively larger variation in the Cretaceous. This is planned for a future study, after further increasing the sample sizes.

6) Part of the uncertainties will be less problematic when we can increase the analysis to include further lineages of Myrmeleontiformia. Also additional specimens of long-necked larvae likely to accumulate in the next years should make the sample sizes more comparable to the modern ones.

\section{Conclusions}

(1) Our knowledge of extant larval forms of Crocinae is better than that of many other groups of Neuroptera.

(2) The basic distinction into two types of larvae of Crocinae, namely long-necked and short-necked forms (basically already used by MacLeod 1964), does not have phylogenetic meaning, but may represent two different functional strategies. Short-necked forms may be ancestral, yet it appears that this type of larva also evolved secondarily within the long-necked forms.

(3) Fossil forms do not fall into any of these groups; they share certain similarities of neck and head shape with the long-necked forms, but are very different concerning mandible and trunk shape.

(4) Fossil forms may be larvae of Crocinae, yet it remains uncertain if they represent a now extinct, highly specialised lineage.

(5) Fossil larvae must have had a quite different ecology than the modern larvae of Crocinae.

(6) Fossil larvae with long necks and their specific combination of characters went extinct. With them, we have lost a certain diversity of morphology and ecology. Although it remains unclear whether this concerns the diversity of Crocinae, it definitely concerns the diversity of Myrmeleontiformia.

\section{Acknowledgements}

This study benefited from the support of various institutions and persons. Two anonymous reviewers are thanked for providing helpful comments on the manuscript. Ana Rita Gonçalves, Adrià Miralles, and Asadolla Hosseini Chegeni kindly provided photographs of extant specimens. Fenja I. Haug kindly provided some of the outlines of the heads. The study is supported by the Volkswagen Foundation with a Lichtenberg Professorship. $\mathrm{CH}$ was funded via the LMUexcellent Junior Researcher Fund and an award for equal opportunities for women in research of the LMU Munich. PGP is supported by Capes/Doctoral Program (CAPES/DAAD/CNPQ, Notice no. 15-2017/ Process $\left.\mathrm{n}^{\circ} 88887.161379 / 2017-00\right)$. J. Matthias Starck is thanked for long-time support. We thank all people providing free software. This is LEON publication \#15. 


\section{References}

AsPöck, H. \& Aspöck, U. 2014. Another neuropterological field trip to Morocco. Lacewing News 19, 6-7.

Aspöck, U. \& Aspöck, H. 1999. Kamelhälse, Schlammfliegen, Ameisenlöwen...Wer sind sie? (Insecta: Neuropterida: Raphidoptera, Megaloptera, Neuroptera). Stapfia 60, $1-34$.

AsPöck, U. \& Aspöck, H. 2007. Verbliebene Vielfalt vergangener Blüte. Zur Evolution, Phylogenie und Biodiversität der Neuropterida (Insecta: Endopterygota). Denisia 20, 451-516.

Badano, D., Aspöck, U., Aspöck, H. \& Cerretti, P. 2017. Phylogeny of Myrmeleontiformia based on larval morphology (Neuropterida: Neuroptera). Systematic Entomology 42, 94-117. DOI 10.1111/syen.12200

Badano, D., Engel, M. S., Basso, A., Wang, B. \& Cerretti, P. 2018. Diverse Cretaceous larvae reveal the evolutionary and behavioural history of antlions and lacewings. Nature Communications 9, 3257. DOI 10.1038/s41467-018-05484-y

Badano, D. \& Pantaleoni, R.A. 2014. The larvae of European Myrmeleontidae (Neuroptera). Zootaxa 3762, 1-72.

DOI 10.11646/zootaxa.3762.1.1

Baranov, V., Lewandowski, J. \& Krause, S. 2016. Bioturbation enhances the aerobic respiration of lake sediments in warming lakes. Biology Letters 12, 20160448. DOI 10.1098/rsbl.2016.0448

Baranov, V.A., SchäDEl, M. \& Haug, J.T. 2019. Fly palaeo-evodevo: immature stages of bibionomorphan dipterans in Baltic and Bitterfeld amber. PeerJ 7, e7843.

DOI 10.7717/peerj.7843

Beutel, R.G., Friedrich, F. \& Aspöck, U. 2010. The larval head of Nevrorthidae and the phylogeny of Neuroptera (Insecta). Zoological Journal of the Linnean Society 158, 533-562. DOI 10.1111/j.1096-3642.2009.00560.x

Beutel, R.G., Friedrich, F., Yang, X.-K. \& Ge, S.-Q. 2013. Insect Morphology and Phylogeny: A textbook for students of entomology. 532 pp. De Gruyter, Berlin, Boston. DOI 10.1515/9783110264043

Bonhomme, V., Picq, S., Gaucherel, C. \& Claude, J. 2014. Momocs: outline analysis Using R. Journal of Statistical Software 56, 1-24. DOI 10.18637/jss.v056.i13

Chen, J., Wang, B., Engel, M.S., Wappler, T., Jarzembowski, E.A., Zhang, H., Wang, X., Zheng, X. \& Rust, J. 2014. Extreme adaptations for aquatic ectoparasitism in a Jurassic fly larva. eLife 3, e02844. DOI 10.7554/eLife.02844

Eltringham, H. 1923. On the larva of Pterocroce storeyi, With. (Nemopteridae). Transactions of the Entomological Society of London 71, 263-266. DOI 10.1111/j.1365-2311.1923.tb03336.x

Engel, M.S., Winterton, S.L. \& Breitkreuz, L.C.V. 2018. Phylogeny and evolution of Neuropterida: where have wings of lace taken us? Annual Review of Entomology 63, 531-551. DOI 10.1146/annurev-ento-020117-043127

GEpP, J. 1984. Erforschungsstand der Neuropteren. Larven der Erde (mit einem Schlüssel zur Larvaldiagnose der Familien, einer Übersicht von 340 beschriebenen Larven und 600 Literaturzitaten), 183-239. In GePp, J., AspöcK, H. \& Hölzel, H. (eds) Progress in Worlds Neuropterology. Proceedings of the First International Symposium on Neuropterology, Graz.

Gerstaecker, A. 1894. Ueber neue und weniger gekannte Neuropteren aus der Familie Megaloptera Burm. Mitt[h] eilungen aus dem Naturwissenschaftlichen Verein für NeuVorpommern und Rügen 25, 93-173.

Ghosh, C.C. 1910. XXVII. Entomological notes. Croce filipennis, Westw. Journal of the Bombay Natural History Society 20, 530-532.

GrIFFINI, A. 1895. Nemoptera baudii, nuova specie di Neurottero dell'isola di Cipro. Bollettino dei Musei di Zoologia e di Anatomia Comparata della R. Università di Torino 10(214), $1-3$.

Grimaldi, D. \& Engel, M.S. 2005. Evolution of the insects. 772 pp. Cambridge University Press, New York.

Hallmann, C.A., Sorg, M., Jongejans, E., Siepel, H., Hofland, N., Schwan, H., Stenmans, W., Müller, A., Sumser, H., Hörren, T., Goulson, D \& DE Kroon, H. 2017. More than 75 percent decline over 27 years in total flying insect biomass in protected areas. PloS ONE 12, e0185809.

DOI 10.1371/journal.pone.0185809

Haug, C., Nyborg, T. \& Vega, F.J. 2013. An exceptionally preserved upogebiid (Decapoda: Reptantia) from the Eocene of California. Bolétin de la Sociedad Geológica Mexicana 65, 235-248. DOI 10.18268/BSGM2013v65n2a5

Haug, C., Herrera Flórez, A.F., Müller, P. \& Haug, J.T. 2019a. Cretaceous chimera - an unusual 100-million-year old neuropteran larva from the "experimental phase" of insect evolution. Palaeodiversity 12, 1-11. DOI 10.18476/pale.v12.a1

Haug, G.T., Haug, C., Pazinato, P.G., Braig, F., Perrichot, V., Gröhn, C., Müller, P. \& Haug, J.T. 2020a. The decline of silky lacewings and morphological diversity of long-nosed antlion larvae through time. Palaeontologia Electronica 23(2), a39. DOI 10.26879/1029

HaUg, J.T. \& Haug, C. 2019. Beetle larvae with unusually large terminal ends and a fossil that beats them all (Scraptiidae, Coleoptera). PeerJ 7, e7871. DOI 10.7717/peerj.7871

Haug, J.T., Müller, P. \& Haug, C. 2019b. A 100-million-year old slim insectan predator with massive venom-injecting stylets - a new type of neuropteran larva from Burmese amber. Bulletin of Geosciences 94, 431-440.

DOI 10.3140/bull.geosci.1753

Haug, J.T., Baranov, V., Schädel, M., Müller, P., Gröhn, P. \& HaUG, C. 2020b. Challenges for understanding lacewings: how to deal with the incomplete data from extant and fossil larvae of Nevrorthidae? (Neuroptera). Fragmenta entomologica 52, 137-167. DOI 10.4081/fe.2020.472

Heckman, C.W. 2017. Neuroptera (including Megaloptera), Encyclopedia of South American Aquatic Insects. 621 pp. Springer International Publishing, Cham.

DOI 10.1007/978-3-319-35125-4

Herrera-Flórez, A.F., Braig, F., Haug, C., Neumann, C., WunDERLICH, J., HöRNIG, M.K. \& HAUG, J.T. 2020a. Identifying the oldest larva of a myrmeleontiformian lacewing - a morphometric approach. Acta Palaeontologica Polonica 65, 235250. DOI 10.4202/app.00662.2019 
Herrera-Flórez, A.F., Haug, C., Burmeister, E.-G. \& Haug, J.T. 2020b. A neuropteran insect with the relatively longest prothorax: the "giraffe" among insects is the larva of a Necrophylus species from Libya. Spixiana 43, 305-314.

Hölker, F., Vanni, M.J., Kuiper, J.J., Meile, C., Grossart, H.-P., Stief, P., Adrian, R., Lorke, A., Dellwig, O., Brand, A., Hupfer, M., Moois, W.M., Nützmann, G. \& Lewandowski, J. 2015. Tube-dwelling invertebrates: tiny ecosystem engineers have large effects in lake ecosystems. Ecological Monographs 85, 333-351. DOI 10.1890/14-1160.1

Hölzel, H. 1975. Revision der Netzflügler-Unterfamilie Crocinae (Neuroptera: Nemopteridae). Entomologica Germanica 2, 44-97.

Hölzel, H. 1999. Die Nemopteriden (Fadenhafte) Arabiens. Stapfia 60, 129-146.

Hörnig, M., Sombke, A., Haug, C., Harzsch, S. \& Haug, J.T. 2016. What nymphal morphology can tell us about parental investment - a group of cockroach hatchlings in Baltic amber documented by a multi-method approach. Palaeontologia Electronica 19.1.6A, 1-20. DOI 10.26879/571

Imms, A.D. 1911. X. Contributions to a knowledge of the structure and biology of some Indian Insects.-I. On the life-history of Croce filipennis, Westw. (Order Neuroptera, Fam. Hemerobiidæ). Transactions of the Linnean Society of London, $2^{\text {nd }}$ Series: Zoology 11(10), 151-160.

DOI 10.1111/j.1096-3642.1911.tb00190.x

Imms, A.D. 1923. A General Textbook of Entomology. 736 pp., Methuen \& Co., London.

Imms, A.D. 1930. A General Textbook of Entomology. 703 pp., Methuen \& Co., London.

IwatA, H. \& UKAI, Y. 2002. SHAPE: A computer program package for quantitative evaluation of biological shapes based on elliptic Fourier descriptors. Journal of Heredity 93, 384-385. DOI 10.1093/jhered/93.5.384

Kimmins, D.E. 1929. An Egyptian cave-dwelling insect. Natural History Magazine 1929, 133-136.

KLUG, J.C.F. 1836. Versuch einer systematischen Feststellung der Insecten-Familie: Panorpatae und Auseinandersetzung ihrer Gattungen und Arten. Abhandlungen der Königlichen Akademie der Wissenschaften 1836, 81-108.

Labandeira, C.C., Yang, Q., Santiago-Blay, J.A., Hotton, C.L., Monteiro, A., Wang, Y.-J., Goreva, Y., Shih, C., Siljeström, S., Rose, T.R., Dilcher, D.L. \& Ren, D. 2016. The evolutionary convergence of mid-Mesozoic lacewings and Cenozoic butterflies. Proceedings of the Royal Society $B$ 283, 20152893. DOI 10.1098/rspb.2015.2893

Lister, B.C. \& GARCiA, A. 2018. Climate-driven declines in arthropod abundance restructure a rainforest food web. PNAS 115, E10397-E10406. DOI 10.1073/pnas.1722477115

Lu, X., WANG, B., YANG, S. \& LiU, X. 2019. Early evolution of Nemopteridae illuminated with the first and oldest thread-winged lacewing in Cretaceous amber. Systematic Entomology 44, 262-272. DOI 10.1111/syen.12328

MACLEOD, E.G. 1964. A comparative morphological study of the head capsule and cervix of larval Neuroptera (Insecta). 528 pp. Ph.D. thesis, Harvard University, Cambridge, Massachusetts, USA.
MacLeod, E.G. 1970. The Neuroptera of the Baltic Amber. I. Ascalaphidae, Nymphidae, and Psychopsidae. Psyche: A Journal of Entomology 77(2),147-180.

DOI 10.1155/1970/45459

Makarkin, V.N., Heads, S.W. \& Wedmann, S. 2017. Taxonomic study of the Cretaceous lacewing family Babinskaiidae (Neuroptera: Myrmeleontoidea: Nymphidoidae), with description of new taxa. Cretaceous Research 78, 149-160. DOI 10.1016/j.cretres.2017.06.007

Mansell, M.W. 1976. The larva of Laurhervasia setacea (Klug), (Neuroptera: Nemopteridae: Crocinae) from southern Africa. Journal of the Entomological Society of Southern Africa 39, $153-158$.

Mansell, M.W. 1977. A new genus and species in the Crocinae (Neuroptera: Nemopteridae) from Southern Africa. Journal of the Entomological Society of Southern Africa 40, 195-203.

Mansell, M.W. 1980. The Crocinae of southern Africa (Neuroptera: Nemopteridae). 1. The genera Laurhervasia Navás and Thysanocroce Withycombe. Journal of the Entomological Society of Southern Africa 43, 341-365.

Mansell, M.W. 1981a. The Crocinae of southern Africa (Neuroptera: Nemopteridae). 2. The genus Concroce Tjeder. Journal of the Entomological Society of Southern Africa 44, 91-106.

Mansell, M.W. 1981b. The Crocinae of southern Africa (Neuroptera: Nemopteridae). 3. The genus Tjederia Mansell, with keys to the southern African Crocinae. Journal of the Entomological Society of Southern Africa 44, 245-257.

Mansell, M.W. 1983a. A revision of the Australian Crocinae (Neuroptera: Nemopteridae). Australian Journal of Zoology 31, 607-627. DOI 10.1071/ZO9830607

Mansell, M.W. 1983b. New Crocinae (Neuroptera: Nemopteridae) from South America, with descriptions of larvae. Journal of the Entomological Society of Southern Africa 46, 115-130.

Mansell, M.W. 1986. Biogeography and phylogeny of the Crocinae (Neuroptera: Nemopteridae), 77-85. In Gepp, J., Aspöck, H. \& Hölzel, H. (eds) Recent research in neuropterology. Proceedings of the $2^{\text {nd }}$ International Symposium on Neuropterology, Graz.

Mansell, M.W. 2002. Monitoring lacewings (Insecta: Neuroptera) in Southern Africa. Acta Zoologica Academiae Scientiarum Hungaricae 48(2), 165-173.

Marshall, S. 2012. Flies. The natural history and diversity of Diptera. Firefly Press Ltd., Richmond Hill, Ontario.

Maxwell-Lefroy, H. 1909a. Indian insect life: a manual of the insects of the plains (tropical India). Thacker, Spink \& Co., Calcutta.

MaXwell-Lefroy, H. 1909b. No. XXXI. Entomological notes. The Journal of the Bombay Natural History Society 19, 1005-1010.

McKeown, K.C. 1939. A new species of thread-winged lacewing (Family Nemopteridae, Order Neuroptera Planipennia) from Queensland. Records of the Australian Museum 20, 261-263. DOI 10.3853/j.0067-1975.20.1939.575

McLachlan, R. 1898. Descriptions de deux espèces nouvelles de Némoptères du genre Croce McLach. [Névr.]. Bulletin de 
la Société Entomologique de France 1898, 169-171. DOI 10.5962/bhl.part. 16850

Miller, A.B. \& Stange, L.A. 1989. A new species of Moranida Mansell from Venezuela (Neuroptera: Nemopteridae). Insecta Mundi 3, 65-70.

Monserrat, V.J. 1983a. Pterocroce capillaris (Klug, 1836) en Europa (Neur., Plan., Nemopteridae). Neuroptera International 2, 109-128.

Monserrat, V.J. 1983b. Estadios larvarios de los neurópteros ibéricos I: Josandreva sazi (Neur. Plan., Nemopteridae). Speleon 26, 39-51.

Monserrat, V.J. 2008. Nuevos datos sobre algunas especies de Nemopteridae y Crocidae (Insecta: Neuroptera). Heteropterus Revista de Entomología 8, 1-33. DOI 10.3989/graellsia.2008. v64.i2.34

Monserrat, V.J., Triviño, V. \& Acevedo, F. 2012. Los nemoptéridos y crócidos de la Península Ibérica (Insecta: Neuroptera: Nemopteridae, Crocidae). Heteropterus Revista de Entomología 12, 231-255.

NavÁs, L. 1906. XI. Tres Neurópteros nuevos de España. Boletín de la Sociedad Aragonesa de Ciencias Naturales 5, 134-137.

NaVÁs, L. 1912. Neuroptera; Fam. Nemopteridæ. In Wytsman, P. (ed.) Genera Insectorum. Verteneuil, V. \& Desmet, L., Brussels.

NAvÁs, L. 1914. Neuropteros nuevos de Africa. Memorias de la Real Academia de Ciencias y Artes de Barcelona, Series 3, 10, 627-653.

NavÁs, L. 1927a. Nemoptérido (Ins. Neur.) nuevo de América. Revista de la Sociedad Entomológica Argentina 2(3), 3-4.

NAVÁs, L. 1927b. Zur Erforschung des Persischen Golfes (Beitrag Nr. 4). Neuroptera. Entomologische Mitteilungen 16, 183-185.

NaVÁs, L. 1936. Mission Scientifique de l'Omo. Tome III. Fascicule 19. Neuroptera, Embioptera, Plecoptera, Ephemeroptera et Trichoptera. Memoires du Museum National d'Histoire Naturelle, Paris (N.S.) 4, 101-128.

New, T.R. 1989. Planipennia, Lacewings. Handbuch der Zoologie, Vol. 4. Arthropoda: Insecta, Part 30. 132 pp. Walter de Gruyter, Berlin.

New, T.R. 1991. Neuroptera (lacewings), 525-542. In NAumanN, I.D. (ed.) The Insects of Australia. $2^{\text {nd }}$ Edition. Vol. 1. Melbourne University Press, Melbourne.

Pierre, F. 1952. Morphologie, milieu biologique et comportement de trois Crocini nouveaux du Sahara nord-occidental (Planipennes, Nemopteridae). Annales de la Société entomologique de France 119, 1-22.

R CORE TEAm 2014. R: A language and environment for statistical computing. R Foundation for Statistical Computing, Vienna, Austria. http://www.R-project.org/

Richards, O.W. \& Davies, R.G. 1977. Imms' General Textbook of Entomology. 10 $0^{\text {th }}$ edition. 394 pp. Chapman \& Hall, London. DOI 10.1007/978-94-011-6514-3

Riek, E.F. 1970. Neuroptera, 472-494. In Evans, H.E. (ed.) The Insects of Australia. Melbourne University Press, Canberra.

Roux, J.L.F.P. 1833. Lettre relative à divers Coquilles, Crustacés. Insectes, Reptiles et Oiseaux, observés en Égypte; adressée par M. Roux à M. le Baron de Férussac. Annales des Sciences Naturelles: comprenant la physiologie animale et végétale, l'anatomie comparée des deux règnes, zoologie, botanique, minéralogue et la géologie 28, 72-78. DOI 10.5962/bhl.part.8009

Satar, A., Suludere, Z., Candan, D. \& Canbulat, S. 2007. Morphology and surface structure of eggs and first instar larvae of Croce schmidti (Navás, 1927) (Neuroptera: Nemopteridae). Zootaxa 1554, 49-55.

DOI 10.11646/zootaxa.1554.1.4

Schaum, H.R. 1857. Necrophilus arenarius Roux, die muthmassliche Larve von Nemoptera. Berliner entomologische Zeitschrift 1, 1-9.

DOI 10.1002/mmnd.48018570105

Seibold, S., Gossner, M.M., Simons, N.K., Blüthgen, N., Müller, J., Ambarli, D., Ammer, C., Bauhus, J., Fischer, M., Habel, J.C., Linsenmair, K.E., Nauss, T., Penone, C., Prati, D., Schall, P., Schulze, E.-D., Vogt, J., Wöllauer, S. \& Weisser, W.W. 2019. Arthropod decline in grasslands and forests is associated with landscape-level drivers. Nature 574, 671-674. DOI 10.1038/s41586-019-1684-3

SHARP, D. 1895. Insects. Part I. Introduction, Aptera, Orthoptera, Neurtoptera, and a portion of Hymenoptera (Sessiliventres et Parasitica), 83-565. In HARMer, S.F. \& Shipley, A.E. (eds) The Cambridge Natural History 5. Macmillian and Co., London.

Sinclair, B.J. 1992. A phylogenetic interpretation of the Brachycera (Diptera) based on the larval mandible and associated mouthpart structures. Systematic Entomology 17, 233-252. DOI 10.1111/j.1365-3113.1992.tb00335.x

STEP, E. 1916. Marvels of Insect Life. 486 pp. Hutchinson \& Co., London.

Suludere, Z., Satar, A., Candan, S. \& Canbulat, S. 2006. Morphology and surface structure of eggs and first instar larvae of Dielocroce baudii (Neuroptera: Nemopteridae) from Turkey. Entomological News 117, 521-530. DOI 10.3157/0013-872X(2006)117[521:MASSOE]2.0.CO;2

TJeder, B. 1967. Neuroptera-Planipennia. The Lacewings of Southern Africa. 6. Family Nemopteridae, 290-501. In Hanström, B., Brinck, P. \& Rudebec, G. (eds) South African Animal Life. Swedish Natural Science Research Council, Stockholm 13.

Tröger, E.J. 1993. Die Larve von Nemoptera coa (Linnaeus, 1758) (Neuropteroidea, Planipennia). Deutsche Entomologische Zeitschrift, Neue Folge 40, 357-368.

DOI 10.1002/mmnd.4800400218

Tusun, S. \& SATAR, A. 2016. Morphology, surface structure and sensory receptors of larvae of Dielocroce ephemera (Gerstaecker, 1894) (Neuroptera: Nemopteridae). Entomological News 126, 144-149.

DOI 10.3157/021.126.0211

Ulyshen, M.D. 2018. Saproxylic insects: diversity, ecology and conservation, Zoological Monographs. 884 pp. Springer, Berlin, Heidelberg, New York, NY.

DOI 10.1007/978-3-319-75937-1

Vasilikopoulos, A., Misof, B., Meusemann, K., Lieberz, D., Flouri, T., Beutel, R.G., Niehuis, O., Wappler, T., Rust, J., 
Peters, R.S., Donath, A., Podsiadlowski, L., Mayer, C., Bartel, D., Böhm, A., Liu, S., Kapli, P., Greve, C., Jepson, J.E., Liu, X., Zhou, X., Aspöcк, H. \& Aspöck, U. 2020. An integrative phylogenomic approach to elucidate the evolutionary history and divergence times of Neuropterida (Insecta: Holometabola). BMC Evolutionary Biology 20(64), 1-24. DOI 10.1186/s12862-020-01631-6

Wang, B., Xia, F., Engel, M.S., Perrichot, V., Shi, G., Zhang, H., Chen, J., Jarzembowski, E.A, Wappler, T. \& Rust, J. 2016. Debris-carrying camouflage among diverse lineages of Cretaceous insects. Science Advances 2(6), e1501918. DOI 10.1126/sciadv. 1501918

Weitschat, W. \& Wichard, W. 2002. Atlas of Plants and Animals in Baltic Amber. 256 pp. Dr. Friedrich Pfeil, München.

Westwood, J.O. 1840. An introduction to the modern classification of insects; founded on the natural habitats and corresponding organisation of the different families, vol. 2. Longman, Orme, Brown, Green, and Longmans, London. DOI 10.5962/bhl.title. 12455

Westwood, J.O. 1841. A monograph on the genus Nematoptera. Proceedings of the Zoological Society of London 9, 9-14.

WheELER, W.M. 1929. Is Necrophylus arenarius Roux the larva of Pterocroce storeyi Withycombe. Psyche 36, 313-320. DOI 10.1155/1929/43184

Winterton, S.L., Hardy, N.B. \& Wiegmann, B.M. 2010. On wings of lace: phylogeny and Bayesian divergence time estimates of Neuropterida (Insecta) based on morphological and molecular data. Systematic Entomology 35, 349-378. DOI 10.1111/j.1365-3113.2010.00521.x
Winterton, S.L., Lemmon, A.R., Gillung, J.P., Garzon, I.J., Badano, D., Bakkes, D.K., BreitKreuz, L.C.V., Engel, M.S., Lemmon, E.M., Liu, X., Machado, R.J.P., Skevington, J.H. \& OswaLD, J.D. 2018. Evolution of lacewings and allied orders using anchored phylogenomics (Neuroptera, Megaloptera, Raphidioptera). Systematic Entomology 43, 330-354. DOI 10.1111/syen. 12278

Withyсомвe, C.L. 1922. Notes on the biology of some British Neuroptera (Planipennia). Transactions of the Entomological Society of London 70, 501-594. DOI 10.1111/j.1365-2311.1923.tb02844.x

Withycombe, C.L. 1923. Systematic notes on the Crocini (Nemopteridae), with descriptions of new genera and species. Transactions of the Entomological Society of London 71, 269-287. DOI 10.1111/j.1365-2311.1923.tb03337.x

Wiтнусомве, C.L. 1925. XV. Some aspects of the biology and morphology of the Neuroptera. With special reference to the immature stages and their possible phylogenetic significance. Transactions of the Royal Entomological Society of London 72, 303-411. DOI 10.1111/j.1365-2311.1925.tb03362.x

WitMER, L.M. 1995. The extant phylogenetic bracket and the importance of reconstructing soft tissues in fossils, 19-33. In Thomason, J.J. (ed.) Functional Morphology in Vertebrate Paleontology. Cambridge University Press, Cambridge.

XIA, F., Yang, G., Zhang, Q., ShI, G. \& Wang, B. 2015. Amber: Life Through Time and Space. 196 pp. Science Press, Beijing.

Zhang, W.W. 2017. Frozen dimensions. The fossil insects and other invertebrates in amber. $692 \mathrm{pp}$. Chongqing University Press, Chongqing. [in Chinese]

\section{Electronic supplementary data}

Suppl. Figure 1. Dataset for shape analysis of mandibles. Suppl. Figure 2. Dataset for shape analysis of heads. Suppl. Figure 3. Dataset for shape analysis of necks. Suppl. Figure 4. Dataset for shape analysis of trunks. Suppl. Figure 5. Dataset for shape analysis of total bodies.

Suppl. Figure 6. Graphical representation of factor loadings of mandibles. Suppl. Figure 7. Graphical representation of factor loadings of heads. Suppl. Figure 8. Graphical representation of factor loadings of necks.

Suppl. Figure 9. Graphical representation of factor loadings of trunks.

Suppl. Figure 10. Graphical representation of factor loadings of total bodies.

Suppl. Text 1. Outcome of the shape analysis of mandibles.

Suppl. Text 2. Outcome of the shape analysis of heads.

Suppl. Text 3. Outcome of the shape analysis of necks.

Suppl. Text 4. Outcome of the shape analysis of trunks.

Suppl. Text 5. Outcome of the shape analysis of total bodies.

Suppl. Table 1. Specimens analysed in this study; specimen no. refers to specimen numbers as mentioned in the text.

Suppl. Table 2. PC values describing the shape of all mandibles.

Suppl. Table 3. PC values describing the shape of all heads, necks, trunks and total bodies. 